\title{
Phylogeography, genetic structure and diversity in the endangered bearded vulture (Gypaetus barbatus, L.) as revealed by mitochondrial DNA
}

\author{
JOSÉ A. GODOY, * JUAN J. NEGRO,†FERNANDO HIRALDO † and JOSÉ A. DONÁZAR† \\ *Laboratory of Molecular Ecology and †Department of Applied Biology, Estación Biológica Doñana, CSIC, Pabellón del Perú, Avda \\ María Luisa, s/n. 41013 Seville, Spain
}

\begin{abstract}
Bearded vulture populations in the Western Palearctic have experienced a severe decline during the last two centuries that has led to the near extinction of the species in Europe. In this study we analyse the sequence variation at the mitochondrial control region throughout the species range to infer its recent evolutionary history and to evaluate the current genetic status of the species. This study became possible through the extensive use of museum specimens to study populations now extinct. Phylogenetic analysis revealed the existence of two divergent mitochondrial lineages, lineage A occurring mainly in Western European populations and lineage B in African, Eastern European and Central Asian populations. The relative frequencies of haplotypes belonging to each lineage in the different populations show a steep East-West clinal distribution with maximal mixture of the two lineages in the Alps and Greece populations. A genealogical signature for population growth was found for lineage B, but not for lineage A; futhermore the Clade B haplotypes in western populations and clade A haplo-types in eastern populations are recently derived, as revealed by their peripheral location in median-joining haplotype networks. This phylogeographical pattern suggests allopatric differentiation of the two lineages in separate Mediterranean and African or Asian glacial refugia, followed by range expansion from the latter leading to two secondary contact suture zones in Central Europe and North Africa. High levels of among-population differentiation were observed, although these were not correlated with geographical distance. Due to the marked genetic structure, extinction of Central European populations in the last century re-sulted in the loss of a major portion of the genetic diversity of the species. We also found direct evidence for the effect of drift altering the genetic composition of the remnant Pyrenean population after the demographic bottleneck of the last century. Our results argue for the management of the species as a single population, given the apparent ecological exchangeability of extant stocks, and support the ongoing reintroduction of mixed ancestry birds in the Alps and planned reintroductions in Southern Spain.
\end{abstract}

Keywords: ancient DNA, conservation genetics, genetic structure, Gypaetus barbatus, mitochondrial DNA, phylogeography

\section{Introduction}

The bearded vulture (Gypaetus barbatus) inhabits highaltitude mountain ranges in the Old World, from the

Correspondence: José A. Godoy. Fax: + 349546211 25; E-mail: godoy@cica.es
Iberian Peninsula to China and south to the Drakensberg Mountains in South Africa. In Africa the species has a discontinuous and peripheral distribution with populations in South Africa and Lesotho, Ethiopia and Morocco (Mundy et al. 1992), the latter of which may be on the brink of extinction (Godino et al. 2003). Bearded vultures are widespread in Central Asian mountains, where the 
stronghold of the species is considered to be. In contrast, the species experienced severe demographic declines in Europe. Populations in the Alps, the Balkans, Greece and Southern Spain have run extinct during the 20th century, due mainly to human persecution, through hunting and poisoning. Currently, the only remnant European populations are in Corsica and Crete (less than 10 breeding pairs each; Thibault et al. 1992; Xirouchakis \& Nikolakakis 2002) and in the Pyrenees (300-400 individuals, around 100 breeding pairs) (R. Heredia unpublished; Heredia \& Heredia 1991). In situ conservation efforts were initiated during recent decades in several countries to preserve the remaining populations. In addition, a captive breeding programme has been implemented by a multinational coalition to repopulate the Alps. The captive stock is composed mainly of individuals of Eastern European or Asian origin. So far, more than 100 captive-bred individuals have been released to the wild and some have already mated and reproduced. Given the success of the Alps reintroduction project, a second release site has been chosen in the Sierra de Cazorla, where the last Southern Spanish population was extirpated in 1987.

The knowledge of the evolutionary history and genetic status of the species is deemed critical for the success of ex situ and in situ conservation programmes, because it allows the definition of management units and the design of management strategies aimed at minimizing genetic erosion while preserving subspecific distinctiveness (Haig 1998; Hedrick 2001). Current genetic patterns in a species are shaped both by historical and contemporary factors that affect its biogeography and its demography. The relative contributions of historic and contemporary factors in shaping the genetic makeup of the species are not easy to disentangle, but several strategies have been proposed (Templeton 1998; Bernatchez 2001; Knowles \& Maddison 2002). A combination of a series of analyses at different temporal scales, including haplotype relatedness, demographic history and population genetics, might be necessary to describe not only a geographical structure but to also investigate the historic or contemporary processes that originate it (Althoff \& Pellmyr 2002; Bernatchez 2001).

Previous genetic studies of bearded vultures have shown low levels of genetic diversity in the Pyrenean population based on multilocus DNA fingerprinting (Negro \& Torres 1999) and differentiation between the Pyrenean and the captive population based on microsatellite markers (Gautschi et al. 2003). More extensive analyses that include the now extinct European populations are now possible through the use of museum specimens and adequate molecular markers and DNA extraction techniques (Leeton et al. 1993; Roy et al. 1994; Mundy et al. 1997).

Here we report the variation in the mitochondrial control region found after a wide survey that includes a major portion of the current and past distribution range of the species. The use of museum specimens, at a scale seldom seen in previous studies, has allowed the analysis of now extinct populations and the direct addressing of changes in population genetic composition through time. The recent evolutionary history of the species is reconstructed by testing alternative phylogeographical hypotheses; the past population structure is described and discussed in relation to the biology of the species, and finally the genetic diversity of the different populations is estimated. In the case of the remnant Pyrenean population, the comparison of historic and contemporary samples enabled us to test the hypothesis that the bottleneck of the last century has affected its genetic composition and diversity. With this information the definition of a management strategy for the species becomes possible, and specific questions concerning the suitability of a mixed ancestry captive breeding programme, the reintroduction of birds of Asian ancestry in Europe, the expected gene flow between reintroduced and remnant population and the risks for genetic depauperation of remnant populations are addressed.

\section{Materials and methods}

\section{Samples}

A total of 172 specimens of bearded vulture (Gypaetus barbatus) have been analysed covering a major portion of the current and past distribution range of the species. Of these, 57 blood/tissue samples and three feathers are contemporary, whereas 104 skin/feather and eight footpad samples are from museum specimens, the only available source for extinct populations (Appendix I). Contemporary living or dead individuals were sampled by collecting blood or muscular tissue, respectively. Blood and tissue samples were stored in ethanol or modified lysis buffer (Seutin et al. 1991). Either the tip of a covert feather and surrounding skin or pieces of the footpad (Mundy et al. 1997) were used as the source of DNA from museum specimens. Several samples came from individuals in the Alps Captive Breeding Programme; in these cases, recorded pedigree information was taken into account to include all founding haplotypes and to avoid sampling the same mitochondrial lineage more than once (Frey et al. 1995). Whenever possible samples were assigned to groups according to their geographical origin and these groups were regarded as populations for population-genetic analysis. In many instances localities of collection were not registered or only broad geographical localizations were available (i.e. former Soviet Union, Russia). With these latter samples, a group of Eastern samples with no precise location was made (EAS). The Pyrenean samples were subdivided into contemporary (NSC) and historic museum samples dated before 1960 (NSH), to evaluate any temporal changes in genetic diversity or gene frequencies. For the other extant 
populations, museum and contemporary samples were pooled when both available.

DNA isolation, polymerase chain reaction (PCR) and sequencing

DNA from blood and tissue samples was extracted with a salting-out (Gemmell \& Akiyama 1996) and a standard phenol-chloroform method, respectively. DNA from museum samples was extracted with DNeasy Tissue Kits (Qiagen) following the manufacturer's instructions, but previous washes in excess NTE $(0.05 \mathrm{~m}$ Tris- $\mathrm{HCl}, 0.01 \mathrm{~m} \mathrm{NaCl}$, 0.02 m EDTA, pH 9.0) were included to remove possible protease or PCR inhibitors (Hall et al. 1997). Contamination with modern DNA or PCR products was monitored by including two extraction blanks in every extraction round and prevented by performing all museum samples extractions in a dedicated 'clean' laboratory, kept free of goodquality DNA and PCR products.

A previous sequence characterization of the whole mitochondrial control region in bearded vulture in a few individuals of diverse origin (Roques et al. 2004) was used to define the target sequence and to design primers for this study. A contiguous segment, centrally located within domain I of the control region, was found to include most of the polymorphic sites observed in a preliminary analysis of a few individuals. Amplification of this approximately 500 base pairs (bp) fragment of the control region was performed using primers tThrF (5'-TTGGTCTTGTAAACCAAARANTGAAG-3') and Fbox-R (5'-GGGTTGCTGRTTTCACGTGAG-3'). Primers QHD1-2F (5'TGCCCCATTATAATGCACTATTCT-3') and Fbox2-R (5'-GTAGGTTCGACAGGAAATGGC-3'), internal to this segment were designed additionally to amplify a shorter $273 \mathrm{bp}$ in museum samples. Maternal mode of inheritance of the sequenced fragment was confirmed with two independent captive families, indicating that they were of mitochondrial origin and not nuclear insertions of mitochondrial sequences.

DNA amplification reactions contained $67 \mathrm{~mm}$ Tris- $\mathrm{HCl}$ $\mathrm{pH}$ 8.0, $16 \mathrm{~mm}\left(\mathrm{NH}_{4}\right)_{2} \mathrm{SO}_{4}, 2.5 \mathrm{~mm} \mathrm{MgCl}_{2}, 0.01 \%$ Tween-20, $0.2 \mathrm{~mm}$ dNTPs, $1 \mu \mathrm{m}$ of each primer, $0.5 \mathrm{U}$ of Taq polymerase and either $50-100 \mathrm{ng}$ of total DNA or $5 \mu \mathrm{L}$ of museum DNA extracts as template. Bovine serum albumin was included at a concentration of $0.1 \mu \mathrm{g} / \mu \mathrm{L}$ for amplification of blood DNA and at $0.8 \mu \mathrm{g} / \mu \mathrm{L}$ for museum DNA. Amplification reactions were performed in an MJ Research thermocycler, Model PTC-100, programmed for an initial denaturation step of $94{ }^{\circ} \mathrm{C}$ for $2 \mathrm{~min}$, followed by 35 cycles of denaturation at $92{ }^{\circ} \mathrm{C}$ for $30 \mathrm{~s}$, annealing at $62-64{ }^{\circ} \mathrm{C}$ (depending on primers) for $30 \mathrm{~s}$ and extension at $72{ }^{\circ} \mathrm{C}$ for $30 \mathrm{~s}$. All reactions were finished with a final extension at $72{ }^{\circ} \mathrm{C}$ for $5 \mathrm{~min}$. To control the performance of the process and monitor for contamination, positive (diluted blood
DNA) and negative (water) DNA controls, respectively, were included with each set of PCR reactions. Additionally, negative extraction controls (mock extractions with no starting material) were included in all amplifications of museum extracts. Amplification products were separated by electrophoresis in 1.5\% agarose gels in TBE buffer ( $89 \mathrm{~mm}$ Tris base, $89 \mathrm{~mm}$ boric acid, $2 \mathrm{~mm}$ EDTA) in the presence of $0.5 \mathrm{mg} / \mathrm{L} \mathrm{EtBr}$. Gels were visualized under UV and photographed with a digital image system (Eastman Kodak Company). PCR products were cleaned by ultrafiltration through Microcon-YM100 or Microcon-PCR (Millipore Corp.) and sequenced on an automated DNA sequencer (ABI-310, Applied Biosystems) using the BigDye Terminator Cycle Sequencing Kit version 2.0 (Applied Biosystems, Inc.) following the manufacturer's instructions, and with the same primers used for the amplification. Sequences were edited, assembled and aligned using the program sequen-

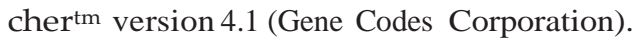

\section{Phylogenetic analysis}

The model of DNA substitution that best fitted the data was selected with the program modeltest, version 3.06 (Posada \& Crandall 1998). The models K80 + I + G ( $\mathrm{I}=0.798$; alpha $=0.525)$ and $\operatorname{TrN}+\mathrm{I}+\mathrm{G}(\mathrm{I}=0.775$, alpha $=0.341)$ were selected by the hierarchical likelihood ratio test and the Akaike Information Index criterion, respectively. Phylogenetic relationships among haplotypes were analysed by distance and maximum likelihood approaches in paup 4.0b10 (Swofford 2002) assuming the model of evolution selected by modeltest. In addition, a Bayesian inference approach using a variant of Markov Chain Monte Carlo was also applied (mrbayes version 3.064; Huelsenbeck \& Ronquist 2001). In this case the tree shown is a consensus of 7000 trees sampled from the posterior distribution with mean branch lengths, once the first 3000 trees were excluded as the 'burn-in'. Statistical support for nodes was estimated by their Bayesian posterior probability (BPP) and by bootstrapping (BS) distance-based trees. Intraspecific genealogies are typically multifurcating and descendant genes coexist with their ancestor. In this situation, as well as in others (recombination, horizontal gene transfer), relationships among DNA sequences are better represented in the form of a network, which also allows the visualization of reverse and parallel homoplasious mutations as cycles or loops (Posada \& Crandall 2001). Median-joining networks were estimated using the software network version 3.1.1.1 (http:// www.fluxus-engineering.com) assigning equal weights to all variable sites and with default values for the epsilon parameter (epsilon $=0$ ). The same final network was obtained when the median-joining algorithm (Bandelt et al. 1999) was run on the reduced data set generated by the reduced median algorithm from a binary transformed data matrix (Bandelt et al. 1995). 
Population sizes and demographic trends

Inferences about population sizes and demographic tendencies can be obtained from genealogies through a number of different approaches (reviewed in Emerson et al. 2001). The parameter theta and the growth rate under an exponential model were estimated simultaneously by maximum likelihood taking into account genealogical information with the program fluctuate 1.3 (Kuhner et al. 1995; Kuhner et al. 1998). Phylogenetic and nonphylogenetic estimates may be considered to reflect historical vs. current demography and their comparison can indicate recent changes in demographic tendencies (Crandall et al. 1999; Vilà et al. 1999). Finally, past demography was investigated through the analysis of the distribution of coalescence events in the genealogy. The shape of the number of lineages through time plots can be interpreted in terms of demographic tendencies, a concave-up plot indicating a stable or declining population and a concave-down plot indicating population growth (Nee et al. 1996). On the other hand, the more recently developed generalized skyline plots provide a nonparametric estimate of effective population size through time obtained from the inferred genealogy (Strimmer \& Pybus 2001). Both LTT and Skyline plots were obtained with the software genie 3.0 (http://evolve.zoo.ox.ac.uk/software/ Genie/).

Population structure and gene flow

Evidence for population genetic structure was assessed using an analysis of molecular variance (amova) (Excoffier et al. 1992) and exact permutation tests (Raymond \& Rousset 1995), as implemented in arlequin 2000 (Schneider et al. 2000). $\Phi_{\mathrm{ST}}$ values between pairs of population were obtained with and without the consideration of the molecular distance among haplotypes. In the latter analysis the influences of the genealogical relationships are neglected and the focus is made on historic dispersal connectivity among populations. A nonparametric permutation test (random permutations of sequences among populations) was used to test whether these statistics are significantly different from zero. Estimates of the absolute number of female migrants $\left(\mathrm{M}_{\mathrm{f}}=\mathrm{N}_{\mathrm{f}} \mathrm{m}_{\mathrm{f}}\right)$ exchanged per generation by each population pair were obtained from the pairwise $\Phi_{\text {ST }}$ values assuming migration-drift equilibrium, applying the formula: $\mathrm{M}_{\mathrm{f}}=\left(1-\Phi_{\mathrm{ST}}\right) / 2 \Phi_{\mathrm{ST}}$. For the computation of geographical distances between populations we first obtained coordinates for reference cities located within the population (SSH: Jaen, NSH: Jaca, ALP: Brig, SAR: Oristano, GRE: Thessaly, CRE: Iraklion, CAS: Naryn, ETH: Adis Ababa) from the TGN website (http:/www.getty.edu/research/ tools/vocabulary/tgn/) and then calculated pairwise distances in kilometres with the module 'Geographic distances' in the r software package (Casgrain \& Legendre 1998). The correlation between the matrix of linearized pairwise differentiation indexes $\left[\Phi_{\mathrm{ST}} /\left(1-\Phi_{\mathrm{ST}}\right)\right]$ and the geographical distance (ln km) was evaluated with Mantel tests using the r software package.

\section{Genetic diversity}

Nucleotide diversity, haplotype diversity and the mean number of differences among sequences and their standard deviations were estimated for the entire sample and different subgroups using the arlequin 2000 software package (Schneider et al. 2000). Differences between historic and contemporary haplotypic diversity in Pyrenean populations were tested for statistical significance with a Welch's test to account for the possible difference in variance between the populations compared (Hoelzel 1999).

\section{Results}

\section{Phylogeography}

The 228 bp segment analysed in 172 samples of bearded vultures includes 28 variable sites, of which three are indels; only one shows three variants and 21 are parsimony informative (Table 1). Nucleotide diversity for the whole data set is estimated in $0.029(\mathrm{SD}=0.015)$, and the mean number of nucleotide differences is $6.65(\mathrm{SD}=3.16)$. These variable sites define a total of 50 haplotypes, resulting in a global haplotype diversity of $0.932(\mathrm{SD}=0.012)$ and a nucleotide diversity of $0.0292(\mathrm{SD}=0.0153)$.

The resolution of the phylogenetic analysis was limited by the large number of haplotypes found and a relatively small number of variable sites, a few of which are highly variable. Nevertheless, a few major phylogenetic associations clearly and consistently showed up as well supported nodes in all analyses performed. Haplotypes are grouped consistently into two major divergent clades, A and B, that differ by a mean of 9.26 substitutions (100\% BPP, 67\% BS) (Fig. 1). A few other internal nodes within clade A are statistically supported, defining at least three sublineages. Much less structure is apparent within clade B, with most groupings having little statistical support. An exception to this is the high Bayesian support obtained for a subclade grouping haplotypes 44 and 46 (100\% BPP, 61\% BS) and moderate Bayesian support for a subclade grouping haplotypes 6, 7 and 50 (92\% BPP, 40\% BS) and for the basal positioning of haplotypes 29 and 30 (90\% BPP, 35\% BS) within clade $\mathrm{B}$. The distinction of the two mayor lineages is also evident in the network analysis (Fig. 2). Homoplasy is reflected in the high number of loops in the network indicating alternative routes for the generation of many of the haplotypes. Within each major clade, internal and terminal nodes can be interpreted as old vs. recently derived haplotypes (Posada, Crandall 2001). The basal 
Table 1 Variable sites found in a fragment of $228 \mathrm{bp}$ of the control region in 172 bearded vultures defining 50 haplotypes and their distribution in populations. Haplotype numbers are shown on the left and nucleotide positions relative to the beginning of the sequence are indicated by digits on the top. Gaps are indicated by -. These sequences have been deposited in GenBank under Accession nos AJ566850-AJ566899.

\begin{tabular}{|c|c|c|c|c|c|c|c|c|c|c|c|c|c|c|c|c|c|c|c|}
\hline \multirow[b]{3}{*}{ Haplotype } & \multirow{3}{*}{$\begin{array}{r}\text { Nucleotide positions } \\
11111111111111122 \\
3335566689913444455557788812 \\
0346735883960068927891603570\end{array}$} & \multicolumn{18}{|c|}{ Populations } \\
\hline & & \multicolumn{5}{|c|}{ Iberian Peninsula } & \multirow[b]{2}{*}{ SAR } & \multirow[b]{2}{*}{ ALP } & \multirow[b]{2}{*}{ GRE } & \multirow[b]{2}{*}{ CRE } & \multirow[b]{2}{*}{ CAU } & \multirow[b]{2}{*}{ CAS } & \multirow[b]{2}{*}{ EAS } & \multirow[b]{2}{*}{ YEM } & \multicolumn{4}{|c|}{ Africa } & \multirow[b]{2}{*}{ Total } \\
\hline & & NSC & NSH & $\mathrm{CSH}$ & SSH & IBH & & & & & & & & & NAF & ETH & SAF & AFR & \\
\hline Gba_H01 & GATACTGCAACTCCACAGACTTCACGTA & 26 & 7 & 1 & & & 1 & 1 & & & & & & & & & & & 36 \\
\hline Gba_H02 & А..Т..ТТ.Т. $\ldots \ldots \ldots$ ТТ.С. & 5 & 1 & & 1 & & & & & & & & & & & & & & 7 \\
\hline Gba_H03 & 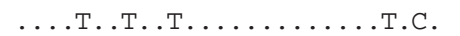 & 1 & 1 & & & & & & & & & & & & & & & & 2 \\
\hline Gba_H04 & ..T.CA..G..T.........T. & & & & & & & & & & & 1 & 1 & & & & & & 2 \\
\hline Gba_H05 & ...T.CAT.G. .T. .........T.C. & & & & & & & & & & & & 1 & & & & & & 1 \\
\hline Gba_H06 & 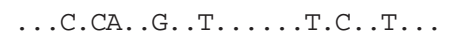 & & & & & & & & & & & & 1 & & & & & & 1 \\
\hline Gba_H07 & 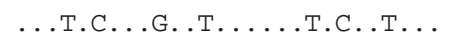 & & & & & & & & & & & & 1 & & & & & & 1 \\
\hline Gba_H08 & . . . C.CATGG.CT . . . . . . . . .T. . & & & & & & & & & & & & 1 & & & & & & 1 \\
\hline Gba_H09 & . .C.CAT.G. .T.G. . . . C..T.C. & & & & & & & & & 1 & & & & & & & & & 1 \\
\hline Gba_H10 & 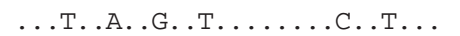 & 1 & & & & & & & & & & & 3 & & & & & & 4 \\
\hline Gba_H11 & ...T.CAT.G. .T. ........... & & & & & & & & & & & & 2 & & & & & & 2 \\
\hline Gba_H12 & ..T.CAT.G. .T. ........ .T. . & & & & & & & & & & & 1 & 1 & & & & & & 2 \\
\hline Gba_H13 & 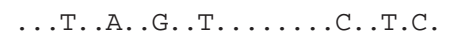 & & & & & & & & & & & 3 & 2 & & & & & & 5 \\
\hline Gba_H14 & ..T.CAT.G.............T.CG & & & & & & & & & & & & 1 & & & & & & 1 \\
\hline Gba_H15 & $\ldots$ Т.СА $\ldots$ Т. $\ldots \ldots$ С. & & & & & & & & & & & & 1 & & & & & & 1 \\
\hline Gba_H16 & ...C.CAT.G. .T. .........T. . & & & & & & & & & & & & 2 & & & & & & 2 \\
\hline Gba_H17 & 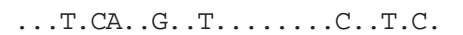 & & & & & & & & & & & & 1 & & & & & & 1 \\
\hline Gba_H18 & ..C.CAT.G. .T.G........T. . & 1 & & & & & & & & & & & & & & & & & 1 \\
\hline Gba_H19 & ..T.C.T.G..T.........ТА. . & & & & & & & & & & & & 1 & & & & & & 1 \\
\hline Gba_H20 & ...C.CAT.G. .T. . ........T.CG & & & & & & & & 1 & & & & & & & & & & 1 \\
\hline Gba_H21 & $\ldots \ldots \ldots \ldots \ldots \ldots \ldots \ldots \ldots \ldots \ldots$ & & & & & & & & & & & & 1 & & & & & & 1 \\
\hline Gba_H22 & . . T.CAT.G. .T. . . . . . . . T. .G & & & & & & & & & & & & 1 & & & & & & 1 \\
\hline Gba_H23 & 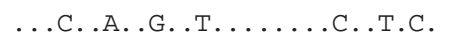 & & & & & & & & & & & 1 & & & & & & & 1 \\
\hline Gba_H24 & А..Т..ТG.Т $\ldots \ldots \ldots \ldots$ Т..СG & & & & 5 & & & 1 & & & & & & & & & & & 6 \\
\hline Gba_H25 & $\ldots$ T.АТ $\ldots \ldots \ldots$ G. $\ldots \ldots$. CG & & & 1 & & & & & 1 & & & & & & & & & & 2 \\
\hline Gba_H26 & . . C.CAT.G. .T.GT . . . . . .T. . & & & & & & & & & 2 & & & & & & & & & 2 \\
\hline Gba_H27 & $\ldots \ldots \ldots \ldots \ldots \ldots \ldots \ldots \ldots c$. & & & & 4 & 1 & & 5 & & & 1 & & & & 1 & & & & 12 \\
\hline Gba_H28 & ..C.CAT.G. .T. .T. ...C. .T. . & & & & & & & & & 1 & & & & & & & & & 1 \\
\hline Gba_H29 & ...CA.G. .T........T.C. & & & & & & & & & & & & & & & 1 & & & 1 \\
\hline Gba_H30 & ....CAT.G..T..........T.C. & & & & & & & & & & & & & & 1 & 5 & 2 & 1 & 9 \\
\hline Gba_H31 & . . C.CAT.G. .T.G. . . . . . .T. . & & & & & & 1 & 12 & & & & & & 1 & & & & & 14 \\
\hline Gba_H32 & 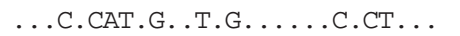 & & & & & & & 2 & & & & & & & & & & & 2 \\
\hline Gba_H33 & $\ldots \ldots$ T.ATG.T. ..........T.CG & & & & & & 10 & 2 & & & & 1 & & & & & & & 13 \\
\hline Gba_H34 & $\ldots \ldots$ T.AT............... & & 1 & & 1 & & & 1 & & & 1 & & & & & & & & 4 \\
\hline Gba_H35 & $\ldots \ldots$ T.TG.T........... & & 2 & & & & 1 & 1 & & & & & & & & & & & 4 \\
\hline Gba_H36 & ...T.TG.T............ & & 1 & & & & 4 & 1 & & & & & & & & & & & 6 \\
\hline Gba_H37 & ...T.AT.......G.G......GG & & & & & & & & & 1 & & & & & & & & & 1 \\
\hline Gba_H38 & 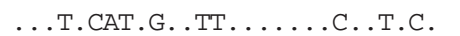 & & & & & & & & & & & 1 & & & & & & & 1 \\
\hline Gba_H39 & 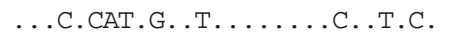 & & & & & & & & & & & 2 & & & & & & & 2 \\
\hline Gba_H40 & $\ldots \ldots$ ATG ....G. . . . CT ... & & & & & & & 1 & & & & & & & & & & & 1 \\
\hline
\end{tabular}




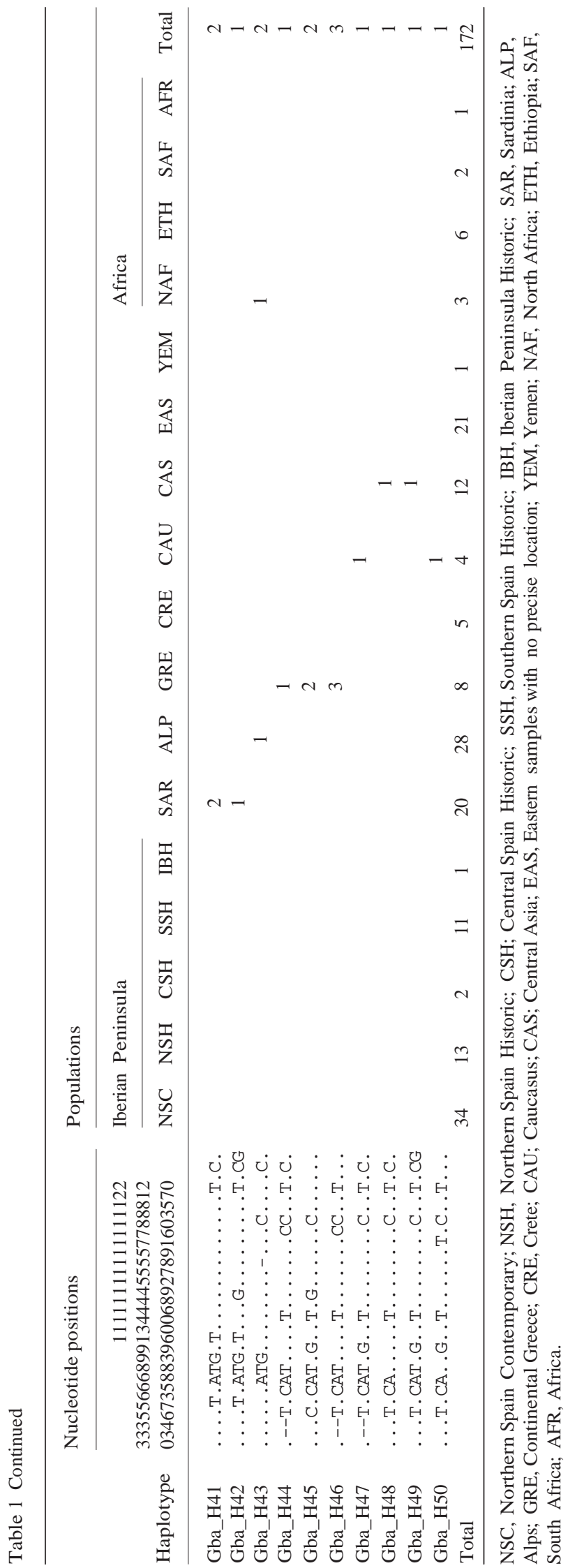

position of haplotypes 29 and 30 in trees is also reflected in their internal positioning within the network.

The rooting of the genealogy was hindered by the lack of suitable outgroups. The bearded vulture's sister species, the Egyptian vulture, shows a highly divergent control region sequence, and alignment is complicated by the presence of tandem repeats (Roques et al. 2003). Control region sequences of more distantly related species, such as those of the Spanish imperial eagle, A. adalberti (GB| AJ567366, Martínez-Cruz et al. unpublished) and crested serpent-eagle, Spilornis cheela (GB|AY140546.1; Horng et al. unpublished), could be aligned and were used as outgroups in different phylogenetic analysis. Overall, the position of the root between clades A and B was supported by more approaches than any other alternative, being the position inferred by midpoint rooting of maximum-likelihood and distance trees, and outgroup rooting of distance and maximum-parsimony trees.

A clear geographical pattern can be superimposed onto the tree and network, with Eastern and African samples classifying preferentially in group B and Western samples in group A. Strict monophyly is not observed, however: a few haplotypes found in western birds do belong to clade B and in two cases (H_21 and H_33) group A haplotypes were found on eastern birds. Haplotype H_21 was detected in sample GbC059 corresponding to individual GB199 from the Breeding Network, recorded as originating from the Former Soviet Union, and haplotype H_33 was found in sample GbS098 from Kazakhstan. Among the several occurrences of clade B haplotypes in western birds, we found H_10 in GB122, an offspring of BG010, recorded as Pyrenean. Because individual GB010 also classified among Asian birds according to its nuclear genotype (Gautschi et al. 2003), this might be a case of sample misidentification or a recent immigrant from Asia in the Pyrenees. Interestingly, clade A haplotypes in eastern populations and clade $B$ haplotypes in western populations tend to be placed as terminal or external nodes in the network, suggesting a recently derived origin, with the only exception of the probably misidentified H_10 haplotype (Fig. 2).

In Africa, two closely related haplotypes classifying in basal positions in clade B (H_30 an H_29) were found in all Ethiopian $(\mathrm{n}=7)$ and South African $(\mathrm{n}=2)$ samples, as well as in an African sample of unknown origin. On the other hand, one of the three samples analysed from North Africa presented the major African haplotype (H_30), whereas the remaining two presented clade A haplotypes shared with Western European populations (H_27 and H_43).

The geographical pattern of haplotype distribution is shown in Fig. 3, indicating a sharp East-West clinal distribution of clade proportions in populations ranging from Iberian Peninsula to Central Asia. More than $95 \%$ of birds from Iberia or Sardinia harboured clade A haplotypes, while 


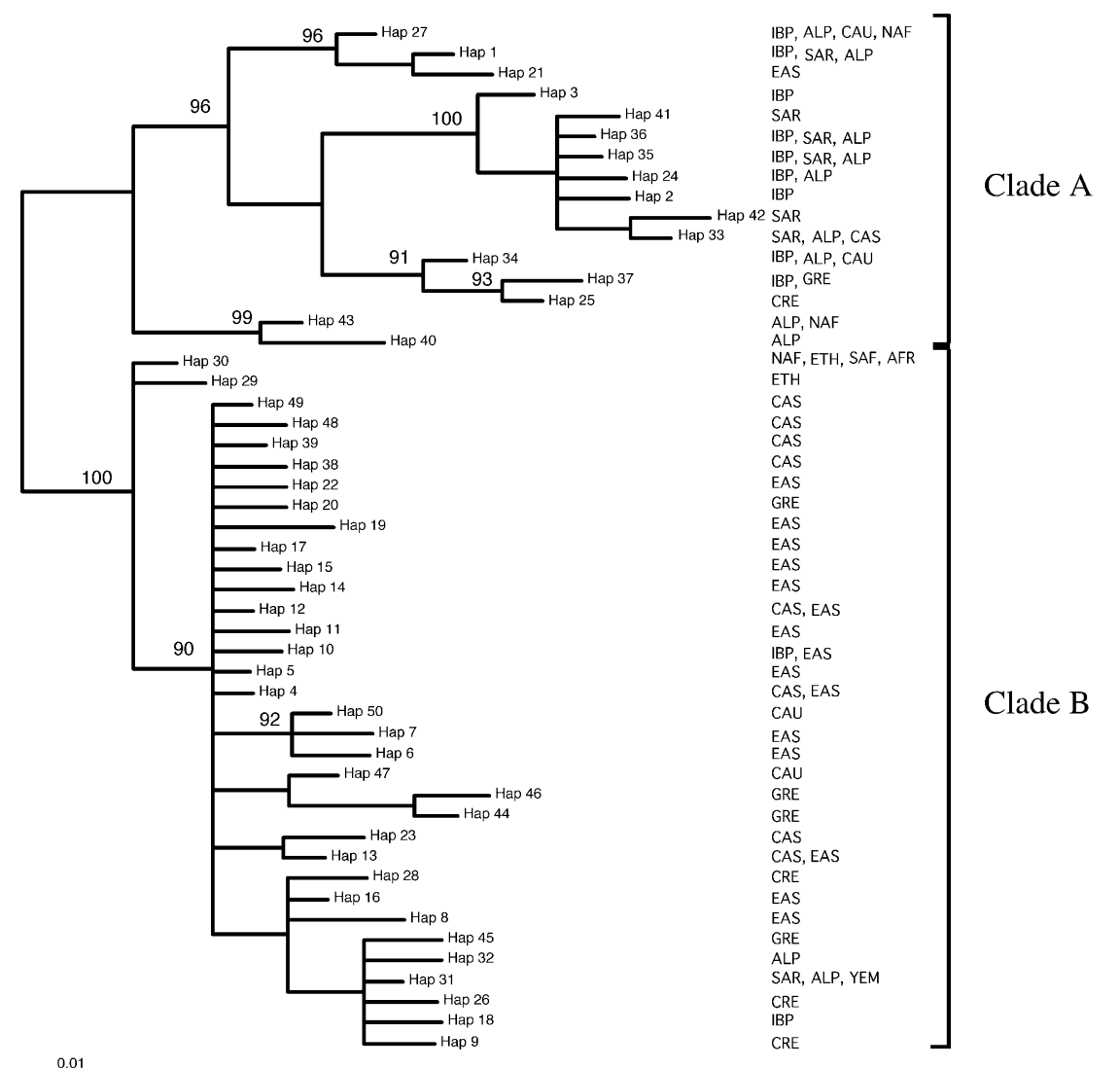

0.01

Clade A haplotypes in Eastern populations

\% Clade B haplotypes in Western populations

臣产 Subsaharian haplotypes
Fig. 1 Phylogenetic relationships among bearded vulture mitochondrial haplotypes. The tree shown is the consensus of 7000 trees sampled from the Bayesian posterior distribution. Numbers at nodes indicate the proportion of times in percentage that a node is found among these trees, as a measure of support. Populations where each haplotype was found are indicated to the right.

Fig. 2 Median joining network of bearded vulture haplotypes. The size of the node indicates the relative frequency of the corresponding haplotype in the whole data set.

Clade A The position of 'misplaced' and African haplotypes is indicated to show their relative external and internal position, respectively. 


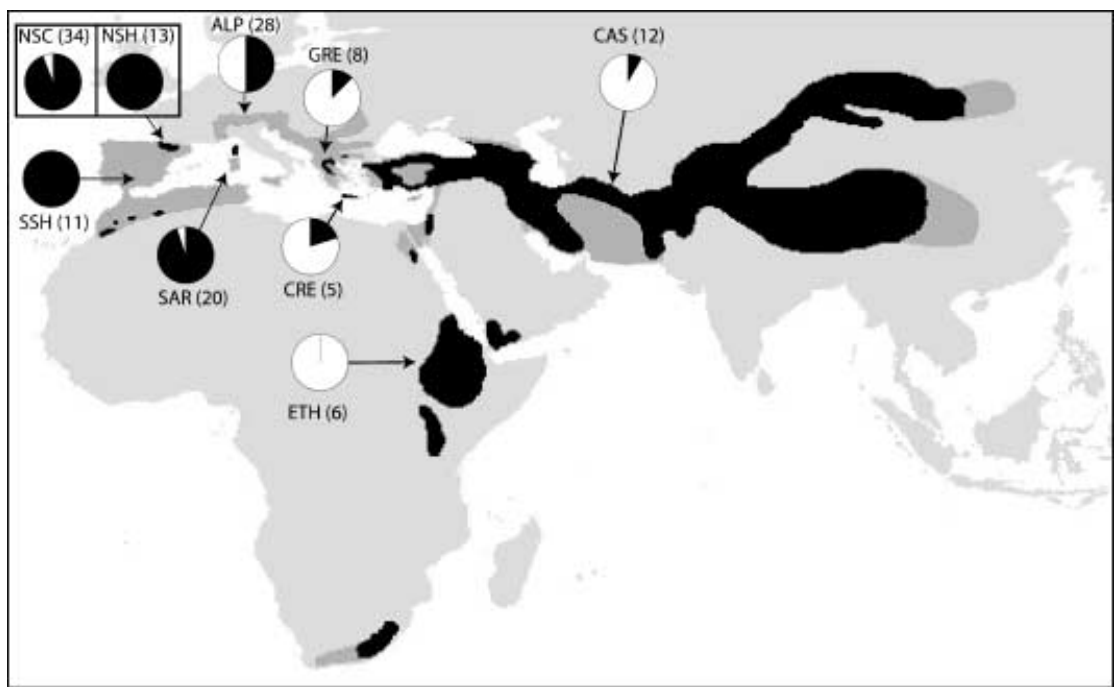

Fig. 3 Map showing the past (grey) and current (black) distribution of the species, based on Mundy et al. (1992) and Heredia \& Heredia (1991). Pie diagrams depict the proportions of clade A (black) and clade B (white) haplotypes in different bearded vulture populations. Numbers in parenthesis refer to sample size.

the opposite was true for birds from central Asia or Africa. Mixing of the two clades was maximal in the Alps, where roughly equal proportions from each clade were found.

The observed pattern might have originated by divergence of the two clades in allopatry and secondary mixing after range expansion, as discussed below. Dating of the population separation event requires a reliable estimation of the evolutionary rate and the assumption of rate constancy and homogeneity. In the absence of an internal calibration, a general uncorrected rate for the hypervariable domain I of the control region in birds is estimated at 20\% per million years (Quinn 1992; Avise \& Walker 1998; Marshall \& Baker 1998). According to this rate, a separation date of 124250 years is estimated from the mean net number of substitutions per site, corrected for within-clade diversity, of 0.02485 . The $95 \%$ confidence interval estimated for the Jukes- Cantor corrected mean is 117950 140150 years (Steel et al. 1996).

\section{Demographic analysis}

The shape of the mismatch distribution function for the whole data set is bimodal, reflecting the deep divergence between the two clades. However, when each clade is analysed separately the shape of the function is unimodal, conforming to the theoretical expectation for a growing population (data not shown). Estimates of theta taking into account genealogical information are $0.0228(\mathrm{SD}=0.0028)$ for clade A and 0.125 (SD = 0.0098) for clade B. Both estimates are higher than those derived from summary statistics (i.e. nucleotide diversity, $\pi$ ) that might be interpreted to reflect more recent demography $\left(\pi_{\mathrm{A}}=0.0189 \pm 0.0105\right.$ and $\left.\Pi_{B}=0.0147 \pm 0.0085\right)$. On the other hand, the maximumlikelihood estimates for the growth parameter under an exponential demographic model, expressed as $1 / \mu$, is negative and low for clade $\mathrm{A}$ and positive and relatively high for clade $\mathrm{B}$ ( $\mathrm{g}=-16.32$ and $\mathrm{g}=253.05$, respectively). Finally, the shapes of the number of lineages through time plots and skyline plots indicate a stationary population for clade $\mathrm{A}$ sequences and a growing population for clade B (Fig. 4). Taking all the information into account, a historic demographic expansion is thus well supported by the sequence data for clade B sequences, while a historically stationary or decreasing population is inferred from clade A sequences.

Population structure and gene flow

With a subset of the samples for which reliable and specific information on location was available, 10 populations with more than five samples could be defined (Table 1). A strong genetic differentiation among populations was indicated by a global $\Phi_{\text {ST }}$ value of 0.553 and 0.260 , for distance or frequency-based analysis, respectively, both being significantly different from zero $(\mathrm{P}<0.00001)$. When the amova analysis was based on a matrix of genetic distances under the most likely model of sequence evolution $(\mathrm{K} 2 \mathrm{P}+\mathrm{G}, \alpha=0.014)$, significant differentiation was recorded between NSH, SSH and SAR and between each of them and all other populations, while more eastern populations, including ALP, were not differentiated among them nor with Ethiopia (data not shown). These results reflect mainly the differential distribution of clades $\mathrm{A}$ and $\mathrm{B}$ haplotypes and the low divergence among clade B haplotypes. On the contrary, when the analysis was based only on haplotype frequencies, significant genetic differentiation was also found between ALP, GRE, CAS, and ETH (Table 2). CRE did not show $\Phi_{\text {ST }}$ values significantly different from zero against any of the other populations, but the exact test excluded the null hypothesis of no differentiation between CRE and SSH, SAR or ALP; in the remaining cases, small sample size might have compromised 
LTT Plot: Clade A

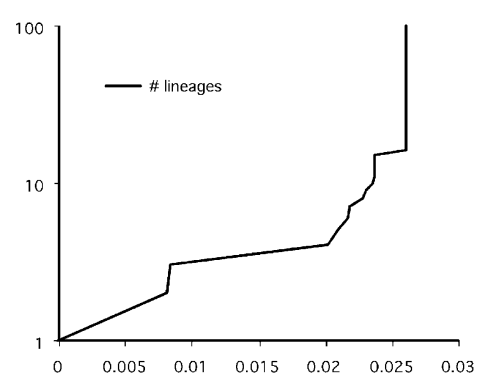

LTT Plot: Clade B

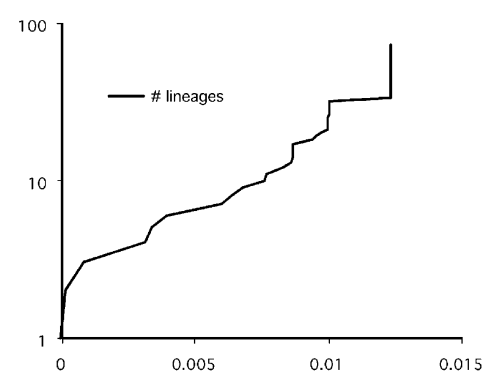

GS Plot: Clade A

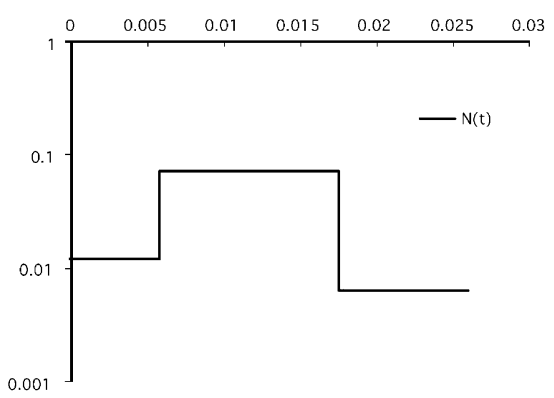

GS Plot: Clade B

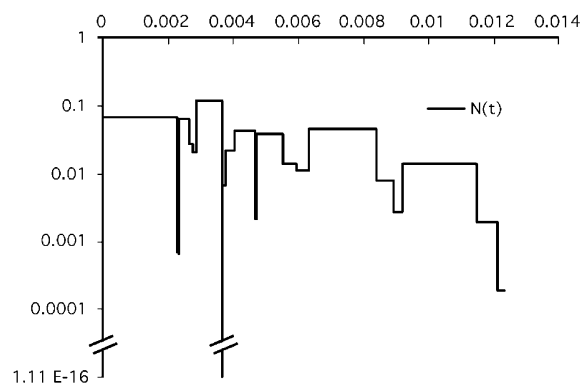

Fig. 4 Demographic history of the two bearded vulture lineages as revealed by lineage-through-time (LTT) and generalized skyline (GS) plots. Horizontal axis represents time since present in substitutions per site and the vertical axis corresponds to the number of lineages in LTT plots and estimated effective population size $\times$ substitution rate in GS plots.

Table 2 Genetic differentiation between bearded vulture populations. Pairwise $\Phi_{\text {ST }}$ values based on haplotype frequencies (above the diagonal) and the corresponding number of female migrants per generation (below the diagonal), assuming mutation-drift equilibrium and an island population model. Significance is evaluated by permuting haplotypes among samples (10 000 permutations) and adjusted for multiple tests by the sequential Bonferroni procedure $(* \mathrm{P}<0.05, * * \mathrm{P}<0.01)$. Significant differentiation in exact differentiation test is shown in bold type in the upper-right half-matrix

\begin{tabular}{lllllllll}
\hline & NSH & SSH & SAR & ALP & GRE & CRE & CAS & ETH \\
\hline NSH & - & $0.2762^{* *}$ & $0.23953^{* *}$ & $0.21611^{* *}$ & $0.21922^{*}$ & 0.210 & $0.17277^{* *}$ & $0.4299^{* *}$ \\
SSH & 1.31 & - & $0.28128^{* *}$ & $0.17351^{*}$ & $0.22186^{*}$ & 0.213 & $0.17405^{* *}$ & $0.44261^{* *}$ \\
SAR & 1.59 & 1.28 & - & $0.18311^{* *}$ & $0.21886^{*}$ & 0.209 & $0.13833^{*}$ & $0.40917^{* *}$ \\
ALP & 1.81 & 2.38 & 2.23 & - & $0.18036^{*}$ & 0.167 & $0.13557^{*}$ & $0.35969^{* *}$ \\
GRE & 1.78 & 1.75 & 1.78 & 2.27 & - & 0.124 & $0.0992^{*}$ & $0.38082^{* *}$ \\
CRE & 1.88 & 1.85 & 1.89 & 2.49 & 3.54 & - & 0.077 & 0.402 \\
CAS & 2.39 & 2.37 & 3.11 & 3.19 & 4.54 & 5.97 & - & $0.3099^{* *}$ \\
ETH & 0.66 & 0.63 & 0.72 & 0.89 & 0.81 & 0.74 & 1.11 & - \\
\hline
\end{tabular}

the power of the tests. The group of eastern samples with no precise location (EAS) did not appear differentiated from CAS in any of the analyses performed, suggesting that these samples might come from the same broad Central Asian population defined in this study.

The combined analysis of pairwise $\Phi_{\text {ST }}$ values did not show a significant correlation with geographical distances (Mantel test, $\mathrm{P}=0.239$; Fig. 5). The relationship between these two variables might be obscured by the widely divergent haplotypic diversity found in different populations. For example, pairwise $\mathrm{F}_{\mathrm{ST}}$ values between the Central Asian population and the rest of the populations were relatively low, even though it shared no haplotypes with western populations. As pointed out by Hedrick (1999), this might be due to high gene diversity $(\mathrm{H}=0.94$ in CAS) imposing a low upper limit on $\mathrm{F}_{\mathrm{ST}}$ values. The opposing effect might bias $\mathrm{F}_{\mathrm{ST}}$ values for ETH where haplotypic diversity was lowest $(\mathrm{H}=0.33)$. The significance of the correlation approached significance after the exclusion of CAS (Mantel test, $\mathrm{P}=0.062$ ), but the exclusion of both CAS and ETH - leaving only European populations - resulted in a nonsignificant correlation (Mantel test, $\mathrm{P}=0.552$ ).

\section{Genetic diversity}

Genetic diversity estimates varied among populations but were especially low for ETH, where six of seven samples shared one haplotype (the major African haplotype H_30), 
Table 3 Estimates of genetic diversity in several bearded vulture populations (for population codes see the legend to Table 1)

\begin{tabular}{|c|c|c|c|c|c|c|}
\hline Population & $\begin{array}{l}\text { No. of } \\
\text { samples }\end{array}$ & $\begin{array}{l}\text { No. of } \\
\text { haplotypes }\end{array}$ & $\begin{array}{l}\text { No. of } \\
\text { polymorphic } \\
\text { sites }\end{array}$ & $\begin{array}{l}\text { Gene } \\
\text { diversity } \\
\text { (SD) }\end{array}$ & $\begin{array}{l}\text { Nucleotidic } \\
\text { diversity } \\
\text { × } 100 \text { (SD) }\end{array}$ & $\begin{array}{l}\text { Mean no } \\
\text { pairwise } \\
\text { differences (SD) }\end{array}$ \\
\hline NSC & 34 & 5 & 14 & $0.40(0.10)$ & $1.21(0.73)$ & $2.76(1.50)$ \\
\hline NSH & 13 & 6 & 10 & $0.72(0.13)$ & $1.69(1.02)$ & 3.85 (2.07) \\
\hline SSH & 11 & 4 & 9 & $0.71(0.10)$ & $1.80(1.10)$ & $4.11(2.22)$ \\
\hline SAR & 20 & 7 & 14 & $0.73(0.09)$ & $1.14(0.71)$ & $2.59(1.45)$ \\
\hline ALP & 28 & 11 & 19 & $0.79(0.07)$ & $2.92(1.58)$ & $6.65(3.24)$ \\
\hline GRE & 8 & 5 & 14 & $0.86(0.11)$ & $2.68(1.62)$ & $6.11(3.25)$ \\
\hline CRE & 5 & 4 & 13 & $0.90(0.16)$ & $2.54(1.71)$ & $5.80(3.34)$ \\
\hline EAS & 21 & 16 & 14 & $0.97(0.02)$ & $1.55(0.91)$ & 3.52 (1.87) \\
\hline CAS & 12 & 9 & 12 & $0.94(0.06)$ & $1.54(0.95)$ & $3.52(1.92)$ \\
\hline ETH & 6 & 2 & 1 & $0.33(0.22)$ & $0.15(0.19)$ & $0.33(0.38)$ \\
\hline
\end{tabular}

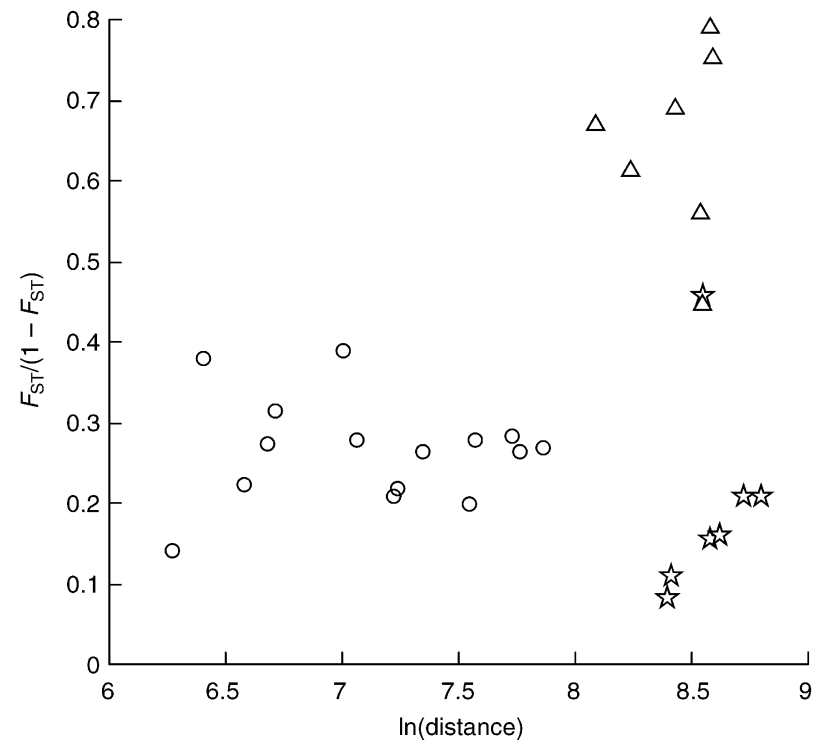

Fig. 5 Genetic differentiation with geographical distance among pairs of bearded vulture populations. Stars and triangles correspond to comparisons involving CAS and ETH populations, respectively.

while the other haplotype differed in one single position from this $(\mathrm{H}=0.33 \pm 0.22 ; \mathrm{P}=0.15 \pm 0.19$ ) (Table 3$)$. At the other extreme, the Central Asian population showed the highest haplotypic diversity $(\mathrm{H}=0.94, \mathrm{SD}=0.06)$, due perhaps in part to the wider geographical area sampled. Haplotypic diversity of European populations ranged from $0.71(\mathrm{SD}=0.10)$ in SSH to $0.90(\mathrm{SD}=0.16)$ in CRE. We found no evidence for lower diversity in islands (Sardinia or Crete), as has been described for other species, including the sister taxon Egyptian vulture in Fuerteventura (Kretzmann et al. 2003; Godoy, Negro, Donazar and Hiraldo, unpublished). On the other hand, nucleotide diversity and mean number of pairwise differences are highest for ALP, GRE and CRE, due to the concurrence of highly divergent clade $\mathrm{A}$ and clade Bhaplotypes in similar proportions.
The direct comparison of current vs. historic diversity in the Pyrenean population allows us to test whether the demographic contraction in the last decades has significantly affected the genetic composition of this population. Historic (NSH) and contemporary (NSC) haplotypic diversity in Pyrenees are significantly different $\left(\mathrm{t}^{\prime}=8.03, \mathrm{P}<0.001\right)$, while the haplotype distributions are only slightly different, as reflected in nonsignificant $\Phi_{\mathrm{ST}}$ values $\left(\Phi_{\mathrm{ST}}=0.043, \mathrm{P}=0.108\right)$ but a significant exact test of differentiation $(\mathrm{P}=0.039)$.

\section{Discussion}

Recent evolutionary history of the species

Patterns of mitochondrial DNA variation in bearded vulture have been shaped by a combination of historic evolutionary and contemporary ecological factors. At the evolutionary level, the phylogenetic analysis of control region sequences reveals the existence of two major evolutionary lineages. Even though a striking geographical pattern is observed in the global distribution of these lineages, a strict geographical separation is not observed. Both lineages coexist in several of the populations analysed reaching almost equal frequencies in the Alps, resulting in polyphyletic groupings. Theory predicts that two populations that become isolated will go progressively from polyphyly to paraphyly and finally to reciprocal monophyly (Avise 2000). Instances in which monophyly is observed allows the inference of a period of evolution in allopatry. However, two alternative historic scenarios might result in polyphyly: (i) a recent separation of the two populations leading to incomplete lineage sorting, or (ii) a secondary admixture following range expansion (Avise 2000). Several lines of evidence indicate that the latter might better explain the pattern observed for the bearded vulture. First, the clinal distribution of clade proportion is not necessarily expected under the lineage-retention hypothesis but a necessary consequence of secondary admixture. 
Second, as illustrated by Avise (2000), the coalescence times of retained lineages in the two populations will predate the vicariant event separating the two populations, while recent immigrants under the secondary contact scenario will present haplotypes identical or closely related to haplotypes in the donor population; the bearded vulture data accommodate to this latter pattern, thus supporting the admixture hypothesis. Third, most of clade B haplotypes in western populations and clade A haplotypes in eastern populations are placed as terminal or otherwise external nodes in the network, suggesting a recent origin, as would be expected for haplotypes in the limits of a expanding range (Posada, Crandall 2001).

Under this interpretation, the two lineages have evolved in allopatry and have been admixed after range expansion. This pattern is common for many other species in Europe (Taberlet et al. 1998; Hewitt 1999) and North America (e.g. Quinn 1992) and have been usually interpreted in relation to the glacial cycles. The Southern European peninsulas have been shown to have acted as glacial refugia for many of the contemporary flora and fauna species and this may also have been the case for bearded vultures. On the other hand, the location of the other refugia in which the second lineage evolved is less clear, although Southern Asia and Africa could be both considered. In support for Africa as the origin of the B lineages is the basal position of the current African haplotypes within this clade, although the statistical support for this is not definitive. In addition, African haplotypes occupy internal positions within the haplotype network, again suggesting that they were ancestors to the other B haplotypes. However, the low haplotype diversity found currently in Africa is far lower than what would be expected for a refugium. A secondary, more recent, bottleneck or a historically low effective population size might account for the current lack of variation in Africa, although independent evidence for this is lacking. If so, the causes for these can only be guessed, but the extreme climatic fluctuations occurring in the continent after the last glacial maximum (Coetzee 1993) and the scarcity of suitable habitat might have seriously impacted the species demography in Africa.

Climatic and geographical factors should be invoked to explain the observed phylogeographical pattern: on one hand, a past geographical isolation that led to the divergence of the two lineages, and on the other hand, a more recent range expansion from Asia towards the West, and also from Eastern and Southern Africa towards the North, that originated the Central Europe and North Africa suture zones, respectively. First, the Sahara desert has probably acted as a permanent barrier for the species. Bearded vultures may have never inhabited the scanty and relatively low-altitude Saharan mountains due to the limitation of nesting sites and lack of food (Mundy et al. 1992). During the last glacial maximum temperatures dropped by $4-9.5^{\circ} \mathrm{C}$ in Africa, causing glaciations on high mountains (including the Atlas, Hoggar, and East African mountains), and a substantial increase in aridity occurred that caused a shift of more that $300 \mathrm{~km}$ southward in the southern boundary of the Sahara desert (Coetzee 1993). Under these conditions bearded vultures were most probably also absent from Northeast Africa so that Eastern or Southern Africa and Mediterranean populations were isolated effectively by a continuous band of thousands of kilometres of unsuitable habitat extending from coast to coast. When the temperature rose after $14000 \mathrm{bp}$, the Atlantic monsoon was re-established which led to more humid conditions, under which the potential habitat in Northeastern Africa became available for bearded vultures. Thus, this key population might have acted as an intermittent stepping-stone that allowed the eventual connection of the two glacial refugia and the formation of the secondary suture zone in North Africa.

The deeper phylogenetic structure and longer branches within clade A when compared to clade B suggests older coalescence times and/or higher historical effective population sizes for western populations. A similar pattern has been observed for other species (reviewed in Taberlet et al. 1998; Hewitt 1999) and indicates that the Western Europe glacial refugia might have served as such in repeated glacial maxima and/or that they have harboured larger populations. However, this observation contrasts with the smaller distribution range of clade A haplotypes and suggests limitations in the recolonization ability from Mediterranean peninsulas. A global pattern of stasis in the demographic history of the western clade is probably reflecting this limitation. On the contrary, clade B occupies a large geographical area and signs of vigorous population growth can be detected in the patterns of mitochondrial sequence variation. For other terrestrial species, range expansion limitations from Mediterranean peninsulas has been attributed to the Pyrenees and the Alps acting as effective barriers (Hewitt 1999; Taberlet et al. 1998). This should not be the case for a bird inhabiting mountains, so that other factors must have affected the differential ability of the two lineages for range expansion. Differences in the geographical continuity of suitable habitat (mountain chains) and/or the availability of food (mainly ungulate carcasses) might be two of such factors.

The pattern of intraspecific genetic variation described in this study does not support the currently accepted distinction of G. b. barbatus and G. b. meridionalis subspecies, with the former covering all Eurasia and North Africa and the latter South and East Africa (Hiraldo et al. 1984). Morphological characters upon which this classification was made (plumage characteristics and body size) might have been fixed by chance in African bearded vultures, and the low haplotypic diversity found suggests a strong founder or bottleneck effect that might have affected both morphological and molecular diversity. Alternatively, 
the morphological characters involved might be subjected to natural selection in Africa. The distinction of subspecies under the complex historic scenario described by the mitochondrial DNA does not seem appropriate; differentiation between the two clades might be viewed as an early stage of allopatric speciation that was aborted by the secondary contact in Central Europe and Northern Africa.

\section{Gene flow among bearded vulture populations}

Significant structuring of genetic diversity was found among most bearded vulture populations, even for population pairs separated by only several hundreds of kilometres, indicating low level of gene flow. Although our results from mitochondrial DNA refer only to female dispersal, similar results obtained with nuclear microsatellite markers suggest this is not a sex-specific pattern (Gautschi 2001). These results contrast with a general pattern of low levels of genetic differentiation among populations of birds (Crochet 2000) and with results obtained for its sister species, the Egyptian vulture (Kretzmann et al. 2003). Such a high level of population differentiation is specially striking for a bird that usually flies long distances in a single day in search for food (Brown 1988) and that can eventually move hundreds of kilometres, as deduced from occasional sightings of birds far from their origin or from any bearded vulture population. A highly phylopatric dispersal behaviour needs to be invoked to explain this apparent paradox and this hypothesis is supported by field observations (R. Antor, unpublished). Phylopatry also explains the existence of a clear phylogeographical pattern: recurrent dispersal has not been sufficient to obscure the primary historic pattern (Hewitt 1996). Despite low estimated rates, significant interchange of individuals among populations occurred in the past and hence might be expected to occur in the future between the reintroduced population in the Alps and the other remnant European populations. The lack of correlation between geographical and genetic distances might in part be an artefact due to the variance in genetic diversity among populations as discussed above, but could also be taken as evidence for the absence of equilibrium between migration and drift over the analysed scale (Hutchinson \& Templeton 1999).

\section{Implications for conservation}

The extinction of genetically differentiated bearded vulture populations has resulted in the loss of a significant proportion of the species genetic diversity and this process of genetic erosion continues as the small populations of Crete and Corsica approach extinction. Remnant European populations, and especially the largest Pyrenean population, should be given maximum priority for conservation because, due to its genetic divergence from the Eastern and African populations, they make a major contribution to the total species' genetic diversity (Petit et al. 1998). The Pyrenean population has already lost a significant proportion of its diversity in the last decades through drift and this process is expected to continue as long as its effective population size remains low and new genetic diversity is not introduced. Immigration from natural remnant populations seems highly unlikely, in view of the estimated low level of historic gene flow and the critical situation of nearby populations. However, migrants from the reintroduced population in the Alps might arrive in the near future if the current trends continue and this population becomes fully established; this would compensate for the loss of genetic diversity through drift and would help to prevent the occurrence of inbreeding depression. While not expected (see below), the occurrence of outbreeding depression should also be monitored.

On the other hand, the identification of conservation units have to take into account both the complex evolutionary history depicted in the mitochondrial DNA and ecological issues. While, according to our interpretation, two evolutionary lineages started diverging some time in the past, this differentiation process was aborted when they came naturally into contact in central Europe, forming a nowextinct hybrid zone. The decline of the species during the last century in Europe has left an apparently large and genetically healthy population in Central Asia and the Pyrenean population, with census sizes around 100 pairs as the largest and most viable European population. These two populations show divergent haplotypes, reflecting historic isolation, but reciprocal monophyly is not observed and thus they cannot be considered as Evolutionary Significant Units as defined by Moritz (1994). They do show different frequencies of mitochondrial haplotype (this study) and also nuclear alleles (Gautschi 2001; Gautschi et al. 2003), indicating low levels of historic gene flow, and thus could be considered Management Units (Moritz 1994). It must be noted, however, that the two populations must have been indirectly connected in the past by gene flow through the now extinct Central European populations. Crandall et al. (2000) argued against this categorization of conservation units based exclusively in genetic distinctiveness; they proposed a broader categorization based on exchangeability - rather than distinctiveness - that also takes into account ecological factors. In this context, the bearded vulture situation might be described as one of recent genetic exchangeability but absence of past genetic exchangeability. On the other hand, there seems to be no evidence to reject ecological exchangeability either past or recent, as no significant differences in life history traits, morphology, habitat or behaviour have been detected between these two populations (Brown 1988; Heredia \& Heredia 1991; Mundy et al. 1992; Cramp \& Perrins 1994). In this situation, the best strategy to preserve adaptive 
diversity and evolutionary processes in bearded vulture would be to treat the species as a single population (Crandall et al. 2000). This interpretation validates the mixed population approach undertaken by the European captive breeding programme and justifies the release of mixed ancestry individuals undertaken in the Alps and future reintroductions in Southern Spain. The future of the species in Europe depends on the effective implementation of conservation strategies both in situ and ex situ that must necessarily consider genetic issues such as those described in this work.

\section{Acknowledgements}

We are greatly indebted to the many people and institutions listed in Appendix I that contributed samples to this study. This project was funded by Grants from the Ministry of Science and Technology (PB97-1264) and the Consejería de Medio Ambiente of the Andalusian Government. The skilful technical assistance and personal motivation of Joaquín Muñoz was critical for the completion of the project. We are also very grateful to Barbara Gautschi for discussions and sharing of samples, to Gabriel Gutiérrez for help with the phylogenetic analysis and to Pedro Jordano, Ciro Rico and Javier Juste for discussions and critical reading of early versions of the manuscript. The comments of two anonymous reviewers helped to improve the final version of the manuscript.

\section{References}

Althoff DM, Pellmyr O (2002) Examining genetic structure in a bogus yucca moth: a sequential approach to phylogeography. Evolution, 56, 1632-1643.

Avise JC (2000) Phylogeography: the History and Formation of Species. Harvard University Press, Cambridge, MA.

Avise JC, Walker D (1998) Pleistocen phylogeographic effects on avian populations and the speciation process. Proceedings of the Royal Society of London Series B, Biological Sciences, 265, 457463.

Bandelt H-J, Foster P, Röhl A (1999) Median-joining networks for inferring intraspecific phylogenies. Molecular Biology and Evolution, 16, 37-48.

Bandelt H-J, Foster P, Sykes BC, Richards MB (1995) Mitochondrial portraits of human populations using median networks. Genetics, 141, 743-753.

Bernatchez L (2001) The evolutionary history of brown trout (Salmo trutta L.) inferred from the phylogeographic, nested clade, and mismatch analyses of mitochondrial DNA variation. Evolution, 55, 351-379.

Brown CJ (1988) A study of the bearded vulture Gypaetus barbatus in Southern Africa. PhD Thesis, Univeristy of Natal Pietermaritzburg, South Africa.

Casgrain P, Legendre P (1998) The $r$ package for multivariate and spatial analysis. University of Montreal, Montreal, Canada. Available at: <http://alize.ere.umontreal.ca/ Casgrain/R/>.

Coetzee JA (1993) African flora since the terminal Jurasic. In: Biology Relationships Between Africa and South America (Ed. by

Goldblatt P), pp. 37-61. Yale University Press, New Haven. Cramp S, Perrins CM (1994) The Birds of the Western Palearctic, Vol. III. Oxford University Press, Oxford.
Crandall KA, Bininda-Emonds ORP, Mace GM, Wayne RK (2000) Considering evolutionary processes in conservation biology. Trends in Ecology and Evolution, 15, 290-295.

Crandall KA, Posada D, Vasco D (1999) Effective population sizes: missing measures and missing concepts. Animal Conservation, 2, 317-319.

Crochet P-A (2000) Genetic structure of avian populations allozymes revisited. Molecular Ecology, 9, 1463-1469. Donázar

JA (1993) Los Buitres Ibericos (ed. Reyero JM). Madrid. Emerson

BC, Paradis E, Thébaud C (2001) Revealing the demographic histories of species using DNA sequences. Trends in Ecology and Evolution, 16, 707-716.

Excoffier L, Smouse PE, Quattro JM (1992) Analysis of molecular variance inferred from metric distances among DNA haplotypes: application to human mitochondrial DNA restriction data. Genetics, 131, 479-491.

Frey H, Knotzinger O, Llopis A (1995) The breeding network - an analysis of the period 1978-95. In: Bearded Vulture Reintroduction Into the Alps, Annual Report 1995 (eds Frey H, Kurzweil J, Bijleveld M), pp. 13-38. Foundation for the Conservation of the Bearded Vulture, Wein.

Gautschi B (2001) Conservation genetics of the Bearded vulture (Gypaetus barbatus). PhD Thesis, University of Zurich.

Gautschi B, Jacob G, Negro JJ et al. (2003) Analysis of relatedness and determination of the source of founders in the captive bearded vulture, Gypaetus barbatus, population. Conservation Genetics, 4, 479-490.

Gemmell N, Akiyama S (1996) An efficient method for the extraction of DNA from vertebrate tissue. TIG, 12, 338-339.

Godino A, Paz JL, Simón MA (2003) Naturalistas españoles localizan en Marruecos 5 quebrantahuesos. Quercus, 205, 4647.

Haig SM (1998) Molecular contributions to conservation. Ecology, 79, 413-425.

Hall LM, Willcox MS, Jones DS (1997) Association of enzyme inhibition with methods of museum skin preparation. Biotechniques, 22, 928-930.

Hedrick PW (1999) Highly variable loci and their interpretation in evolution and conservation. Evolution, 53, 313-318.

Hedrick PW (2001) Conservation genetics: where are we now? Trends in Ecology and Evolution, 16, 629-636.

Heredia R, Heredia B (1991) El quebrantahuesos (Gypaetus barbatus) en los Pirineos. In: Colección Técnica. Ministerio de Agricultura, Pesca y Alimentacion, Madrid.

Hewitt GM (1996) Some genetic consequences of ice ages, and their role in divergence and speciation. Biological Journal of the Linnean Society, 58, 247-276.

Hewitt GM (1999) Post-glacial recolonization of European biota. Biological Journal of the Linnean Society, 68, 87-112.

Hiraldo F, Delibes M, Calderón J (1984) Comments on the taxonomy of the bearded vulture Gypaetus barbatus (Linnaeus, 1758). Bonner Zoologische Beitrage, 35, 91-95.

Hoelzel AR (1999) Impact of population bottlenecks on genetic variation and the importance of life-history; a case study of the northern elephant seal. Biological Journal of the Linnean Society, 68, 23-39.

Huelsenbeck JP, Ronquist F (2001) mrbayes: Bayesian inference of phylogenetic trees. Bioinformatics, 17, 754-755.

Hutchinson DW, Templeton A (1999) Correlation of pairwise genetic and geographic distance measures: inferring the relative influences of gene flow and drift on the distribution of genetic variability. Evolution, 53, 1898-1914. 
Knowles LL, Maddison WP (2002) Statistical phylogeography. Molecular Ecology, 11, 2623-2635.

Kretzmann M, Capote N, Godoy JA, Donázar JA, Negro JJ (2003) Genetically distinct island populations of the Egyptian vulture (Neophron percnopterus). Conservation Genetics, 4, 697706.

Kuhner MK, Yamato J, Felsenstein J (1998) Maximum likelihood estimation of population growth rates based on the coalescent. Genetics, 140, 1421-1430.

Kuhner MK, Yamato J, Felsenstein J (1995) Estimating effective population size and mutation rate from sequence data using Metropolis-Hastings sampling. Genetics, 140, 1421-1430.

Leeton P, Christidis L, Westerman M (1993) Feathers from museum bird skins - a good source of DNA for phylogenetic studies. Condor, 95, 465-466.

Marshall HD, Baker AJ (1998) Rates and patterns of mitochondrial DNA sequence evolution in fringilline finches (Fringilla spp.) and the greenfinch (Carduelis chloris). Molecular Biology and Evolution, 15, 638-646.

Moritz C (1994) Defining 'evolutionary significant units' for conservation. Trends in Ecology and Evolution, 9, 373-375.

Mundy P, Butchart D, Ledger J, Piper S (1992) Bearded vulture, Gypaetus barbatus. In: The Vultures of Africa, pp. 202-219. Academic Press Ltd, London.

Mundy NI, Unitt P, Woodruff DS (1997) Skin from feet of museum specimens as a non-destructive source of DNA for avian genotyping. Auk, 114, 126-129.

Nee S, Holmes EC, Rambaut A, Harvey PH (1996) Inferring population history from molecular phylogenies. In: New Uses for New Phylogenies (eds Harvey PH, Brown AJL, Maynard-Smith J, Nee S), pp. 66-80. Oxford University Press, Oxford.

Negro JJ, Torres MJ (1999) Genetic variability and differentiation of two bearded vulture Gypaetus barbatus populations and implications for reintroduction projects. Biological Conservation, 87, 249-254.

Petit RJ, Mousadik A, Pons AO (1998) Identifying populations for conservation on the basis of genetic markers. Conservation Biology, 12, 844-855.

Posada D, Crandall KA (1998) modeltest: testing the model of DNA substitution. Bioinformatics, 14, 817-818.

Posada D, Crandall KA (2001) Intraspecific gene genealogies: trees grafting into networks. Trends in Ecology and Evolution, 16, 37-45.

Quinn TW (1992) The genetic legacy of Mother Goose - phylogeographic patterns of lesser snow goose Chen caerulescens caerulescens maternal lineages. Molecular Ecology, 1, 105-117.

Raymond M, Rousset F (1995) An exact test from population differentiation. Evolution, 49, 1280-1283.

Roques S, Godoy JA, Hiraldo F, Negro JJ (2004) Organisation and variation of the mitochondrial control region in two vulture species, Gypaetus barbatus and Neophron percnopterus. Journal of Heredity, in press.
Roy MS, Girman DJ, Taylor AC, Wayne RK (1994) The use of museum specimens to reconstruct the genetic variability and relationships of extinct populations. Experientia, 50, 551-557.

Schneider SD, Roessli D, Excoffier L (2000) ARLEQUIN, Version 2.0: a Software for Population Genetic Data Analysis Genetics and Biometry Laboratory. University of Geneva, Switzerland.

Seutin G, White BN, Boag PT (1991) Preservation of avian blood and tissue samples for DNA analyses. Canadian Journal of Zoology, 69, 82-90.

Steel MA, Cooper AC, Penny D (1996) Confidence intervals for the divergence time of two clades. Systematic Biology, 45, 127134.

Strimmer K, Pybus OG (2001) Exploring the demographic history of DNA sequences using the generalized skyline plot. Molecular Biology and Evolution, 18, 2298-2305.

Swofford DL (2002) PAUP* Phylogenetic Analysis Using Parsimony (*and Other Methods), Version 4. Sinauer Associates, Sunderland, MA.

Taberlet P, Fumagalli L, Wust-Saucy AG, Cosson JF (1998) Comparative phylogeography and postglacial colonization routes in Europe. Molecular Ecology, 7, 453-464.

Templeton A (1998) Nested clade analyses of phylogeographic data: testing hypotheses about gene flow and population history. Molecular Ecology, 7, 381-397.

Thibault JC, Vigne JD, Torre J (1992) The diet of young Lammergeiers Gypaetus barbatus in Corsica: its dependence on extensive grazing. Ibis, 135, 203-214.

Vilà C, Amorim IR, Leonard JA et al. (1999) Mitochondrial DNA phylogeography and population history of the grey wolf Canis lupus. Molecular Ecology, 8, 2089-2103.

Xirouchakis S, Nikolakakis M (2002) Conservation implications of the temporal and spatial distribution of bearded vulture Gypaetus barbatus in Crete. Bird Conservation International, 12, 269-280.

This study is one result of the recent incorporation of molecular genetic techniques in our institute through the creation of the Laboratory of Molecular Ecology, which promotes the collaborative interaction between field- and laboratory-based scientists for the study of the ecology and evolutionary biology of wild species of plants and animals. J.A. Godoy acts as coordinator of the laboratory; he is a geneticist whose current interest is in the application of molecular population genetics to the conservation of carnivores and raptors and the study of seed dispersal by frugivorous birds. J.J. Negro, although initially trained as a behavioural ecologist, is also interested in genetic variability issues, hybridization and genetic erosion in small populations. F. Hiraldo is a population ecologist interested in the study and conservation of endangered raptors. J.A. Donázar has conducted research on population dynamics and limiting factors for vultures, both in the New and the Old World. 
Appendix 1

Summary list of samples used in this study

\begin{tabular}{|c|c|c|c|c|c|c|c|c|c|c|}
\hline Sample ID & $\begin{array}{l}\text { Sample } \\
\text { code }\end{array}$ & $\begin{array}{l}\text { Locality/ } \\
\text { area }\end{array}$ & Country & Date & Tissue $^{1}$ & Data $^{2}$ & Haplotype & Population & Contributor ${ }^{3}$ & Sampler \\
\hline Gb-1101048 & GbC001 & Pyrenees & Spain & $1 / 6 / 96$ & B & + & H_01 & NSC & FCQ & R. Antor \\
\hline Gb-1101050 & GbC002 & Pyrenees & Spain & $3 / 5 / 94$ & B & + & H_01 & NSC & FCQ & R. Antor \\
\hline Gb-12002 & GbC003 & Pyrenees & Spain & $12 / 1 / 95$ & B & + & H_01 & NSC & FCQ & R. Antor \\
\hline Gb-12003 & GbC004 & Pyrenees & Spain & 9/2/95 & B & + & H_01 & NSC & FCQ & R. Antor \\
\hline Gb-12004 & GbC005 & Pyrenees & Spain & $30 / 5 / 95$ & B & + & H_01 & NSC & FCQ & R. Antor \\
\hline Gb-12005 & GbC006 & Pyrenees & Spain & $5 / 6 / 96$ & $\mathrm{~B}$ & + & H_01 & NSC & FCQ & R. Antor \\
\hline Gb-12013 & GbC007 & Pyrenees & Spain & 20/5/99 & $\mathrm{B}$ & + & H_02 & NSC & FCQ & R. Antor \\
\hline Gb-12021 & GbC008 & Pyrenees & Spain & $16 / 12 / 94$ & $\mathrm{~B}$ & + & H_01 & NSC & FCQ & R. Antor \\
\hline Gb-12022 & GbC009 & Pyrenees & Spain & $12 / 1 / 95$ & $\mathrm{~B}$ & + & H_01 & NSC & FCQ & R. Antor \\
\hline Gb-12023 & GbC010 & Pyrenees & Spain & $10 / 2 / 95$ & $\mathrm{~B}$ & + & H_01 & NSC & FCQ & R. Antor \\
\hline Gb-12024 & GbC011 & Pyrenees & Spain & $30 / 5 / 95$ & B & + & H_01 & NSC & FCQ & R. Antor \\
\hline Gb-12031 & GbC012 & Pyrenees & Spain & 3/6/99 & B & + & H_01 & NSC & FCQ & R. Antor \\
\hline Gb-12032 & GbC013 & Pyrenees & Spain & 4/5/99 & B & + & H_01 & NSC & FCQ & R. Antor \\
\hline Gb-12033 & GbC014 & Pyrenees & Spain & 21/5/99 & B & + & H_01 & NSC & FCQ & R. Antor \\
\hline Gb-12041 & GbC015 & Pyrenees & Spain & 2/1/95 & $\mathrm{B}$ & + & H_02 & NSC & FCQ & R. Antor \\
\hline Gb-12042 & GbC016 & Pyrenees & Spain & $3 / 2 / 95$ & $\mathrm{~B}$ & + & H_02 & NSC & FCQ & R. Antor \\
\hline Gb-12043 & GbC017 & Pyrenees & Spain & $11 / 2 / 95$ & $\mathrm{~B}$ & + & H_01 & NSC & FCQ & R. Antor \\
\hline Gb-12044 & GbC018 & Pyrenees & Spain & $17 / 5 / 95$ & B & + & H_02 & NSC & FCQ & R. Antor \\
\hline Gb-12049 & GbC019 & Pyrenees & Spain & $15 / 6 / 99$ & B & + & H_03 & NSC & FCQ & R. Antor \\
\hline Gb-12051 & GbC020 & Pyrenees & Spain & 27/5/99 & B & + & H_01 & NSC & FCQ & R. Antor \\
\hline Gb-12052 & GbC021 & Pyrenees & Spain & $5 / 5 / 99$ & B & + & H_01 & NSC & FCQ & R. Antor \\
\hline Gb-12061 & GbC022 & Pyrenees & Spain & $6 / 1 / 95$ & B & + & H_01 & NSC & FCQ & R. Antor \\
\hline Gb-12062 & GbC023 & Pyrenees & Spain & 3/2/95 & B & + & H_01 & NSC & FCQ & R. Antor \\
\hline Gb-12063 & GbC024 & Pyrenees & Spain & $11 / 2 / 95$ & B & + & H_01 & NSC & FCQ & R. Antor \\
\hline Gb-12064 & GbC025 & Pyrenees & Spain & $8 / 7 / 95$ & $\mathrm{~B}$ & + & H_01 & NSC & FCQ & R. Antor \\
\hline Qh.1ZARAGOZA & GbC026 & Pyrenees & Spain & 6/10/93 & M & + & H_01 & NSC & FCQ & R. Antor \\
\hline Qh.4ZARAGOZA & GbC027 & Pyrenees & Spain & $19 / 1 / 98$ & M & + & H_01 & NSC & FCQ & R. Antor \\
\hline BG-005 & GbC028 & Kopetdag & Turkmenistan & $6 / 5 / 98$ & $\mathrm{~B}$ & + & H_04 & CAS & BVBN & - \\
\hline BG-009 & GbC029 & - & Rusia & Contemporary & $\mathrm{B}$ & + & H_05 & EAS & BVBN & - \\
\hline BG-016 & GbC030 & - & Eurasia & $6 / 5 / 98$ & B & + & H_06 & EAS & BVBN & - \\
\hline BG-017 & GbC031 & - & Eurasia & 1999 & $\mathrm{~B}$ & + & H_07 & EAS & BVBN & - \\
\hline BG-040 & GbC032 & - & Eurasia & Contemporary & $\mathrm{B}$ & + & H_08 & EAS & BVBN & - \\
\hline BG-044 & GbC033 & - & Mideast-Asia & Contemporary & B & + & H_04 & EAS & BVBN & - \\
\hline BG-065 & GbC034 & - & Crete & $6 / 5 / 98$ & B & + & H_09 & CRE & BVBN & - \\
\hline BG-070 & GbC035 & - & Asia & Contemporary & $\mathrm{B}$ & + & H_10 & EAS & BVBN & - \\
\hline BG-104 & GbC036 & - & Russia & Contemporary & B & + & H_10 & EAS & BVBN & - \\
\hline BG-105 & GbC037 & - & Former USSR & Contemporary & $\mathrm{B}$ & + & H_11 & EAS & BVBN & - \\
\hline BG-118 & GbC038 & - & Former USSR & Contemporary & B & + & $\mathrm{H} \_12$ & EAS & BVBN & - \\
\hline BG-128 & GbC039 & - & Eurasia & $6 / 5 / 98$ & B & + & H_13 & EAS & BVBN & - \\
\hline
\end{tabular}




\begin{tabular}{|c|c|c|c|c|c|c|c|c|c|c|}
\hline Sample ID & $\begin{array}{l}\text { Sample } \\
\text { code }\end{array}$ & $\begin{array}{l}\text { Locality/ } \\
\text { area }\end{array}$ & Country & Date & Tissue $^{1}$ & Data $^{2}$ & Haplotype & Population & Contributor ${ }^{3}$ & Sampler \\
\hline BG-122 & GbC040 & Pyrenees & Spain & Contemporary & $\mathrm{B}$ & + & H_10 & NSC & BVBN & - \\
\hline BG-124 & GbC041 & - & Eurasia & 23/10/98 & B & + & H_14 & EAS & CCG & A. Llopis \\
\hline BG-130 & GbC042 & - & Former USSR & Contemporary & B & + & H_15 & EAS & BVBN & - \\
\hline BG-131 & GbC043 & - & Eurasia & Contemporary & B & + & H_16 & EAS & CCG & A. Llopis \\
\hline BG-133 & GbC044 & - & Former USSR & Contemporary & B & + & H_17 & EAS & BVBN & - \\
\hline BG-175 & GbC045 & - & Former USSR & Contemporary & B & + & H_10 & EAS & BVBN & - \\
\hline BG-201 & GbC046 & - & Tajikistan & 1999 & B & + & H_12 & CAS & BVBN & - \\
\hline BG-232 & GbC047 & Pyrenees & Spain & 17/6/98 & B & + & H_18 & NSC & CCG & A. Llopis \\
\hline BG-278 & GbC048 & - & Eurasia & 25/6/98 & B & + & H_13 & EAS & CCG & A. Llopis \\
\hline BG-286 & GbC049 & Pyrenees & Spain & 17/6/98 & B & + & H_01 & NSC & CCG & A. Llopis \\
\hline BG-014 & GbC050 & - & Former USSR & Contemporary & B & + & H_16 & EAS & BVBN & - \\
\hline BG-022 & GbC051 & - & Russia & Contemporary & B & + & H_19 & EAS & BVBN & - \\
\hline BG-031 & GbC052 & - & Eurasia & Contemporary & B & + & H_11 & EAS & BVBN & - \\
\hline BG-178 & GbC053 & - & Greece & Contemporary & B & + & H_20 & GRE & BVBN & - \\
\hline BG-199 & GbC054 & - & Former USSR & Contemporary & B & + & H_21 & EAS & BVBN & - \\
\hline BG-204 & GbC055 & - & Russia & Contemporary & B & + & H_22 & EAS & BVBN & - \\
\hline- & GbC056 & Zoo Alma-ata & Kazakhstan & June 1999 & B & + & H_23 & CAS & Zoo Alma-ata & J.A. Donázar \\
\hline- & GbC057 & Zoo Alma-ata & Kazakhstan & June 1999 & B & + & H_13 & CAS & Zoo Alma-ata & J.A. Donázar \\
\hline- & GbC065 & Pyrenees & Spain & 4/6/01 & F & + & H_01 & NSC & - & M. Razin \\
\hline ACC 1996-13 & GbS001 & - & - & & & 1878 & $\mathrm{~S} / \mathrm{F}$ & - & NHMT & A. Margalida \\
\hline ACC 1996-14 & GbS002 & - & Mongolia & 1887 & $\mathrm{~S} / \mathrm{F}$ & + & H_38 & CAS & NHMT & A. Margalida \\
\hline ACC 1996-15 & GbS003 & Baïgorri (Pyr.) & France & 1872 & $\mathrm{~S} / \mathrm{F}$ & + & H_34 & $\mathrm{NSH}$ & NHMT & A. Margalida \\
\hline ACC 1996-16 & GbS004 & - & - & 1871 & $\mathrm{~S} / \mathrm{F}$ & - & & & NHMT & A. Margalida \\
\hline ACC 1996-17 & GbS005 & - & - & 1860 & $\mathrm{~S} / \mathrm{F}$ & - & & & NHMT & A. Margalida \\
\hline ACC 1996-18 & GbS006 & - & - & 1877 & $\mathrm{~S} / \mathrm{F}$ & - & & & NHMT & A. Margalida \\
\hline ACC 1996-19 & GbS007 & - & - & 1872 & $\mathrm{~S} / \mathrm{F}$ & - & & & NHMT & A. Margalida \\
\hline ACC 1996-212 & GbS008 & - & - & 1880 & $\mathrm{~S} / \mathrm{F}$ & - & & & NHMT & A. Margalida \\
\hline- & GbS009 & Pyrenees & Spain & 1966 & $\mathrm{~S} / \mathrm{F}$ & + & H_01 & $\mathrm{NSH}$ & EBD & J. Muñoz \\
\hline- & GbS010 & Pyrenees & Spain & 1966 & $\mathrm{~S} / \mathrm{F}$ & + & H_01 & $\mathrm{NSH}$ & EBD & J. Muñoz \\
\hline- & GbS011 & Pyrenees & Spain & Pre-1950 & $\mathrm{S} / \mathrm{F}$ & + & H_03 & $\mathrm{NSH}$ & - & J.A. Donázar \\
\hline- & GbS012 & Pyrenees & Spain & 1932 & $\mathrm{~S} / \mathrm{F}$ & - & & & - & J.A. Donázar \\
\hline- & GbS013 & Pyrenees & Spain & $1940-1950$ & $\mathrm{~S} / \mathrm{F}$ & + & H_01 & $\mathrm{NSH}$ & - & D. Campión \\
\hline- & GbS014 & Thian Shan & Kazakhstan & 1999 & $\mathrm{~S} / \mathrm{F}$ & + & $\mathrm{H} \_13$ & CAS & - & J.A. Donázar \\
\hline- & GbS015 & Thian Shan & Kazakhstan & 1999 & $\mathrm{~S} / \mathrm{F}$ & + & H_39 & CAS & - & J.A. Donázar \\
\hline- & GbS016 & Thian Shan & Kazakhstan & 1999 & $\mathrm{~S} / \mathrm{F}$ & - & & & - & J.A. Donázar \\
\hline- & GbS017 & Thian Shan & Kazakhstan & 1999 & $\mathrm{~S} / \mathrm{F}$ & - & & & - & J.A. Donázar \\
\hline- & GbS018 & Pyrenees & Spain & 1986 & $\mathrm{~S} / \mathrm{F}$ & + & H_02 & NSC & MNCNM & J.J. Negro \\
\hline Ad.21735 & GbS019 & Jaca (Pyr.) & Spain & Pre-1950 & $\mathrm{S} / \mathrm{F}$ & + & H_01 & $\mathrm{NSH}$ & MNCNM & J.J. Negro \\
\hline Ad.21736 & GbS020 & Unarre (Pyr.) & Spain & 1979 & $\mathrm{~S} / \mathrm{F}$ & + & H_01 & NSC & MNCNM & J.J. Negro \\
\hline 7661 Ad.Benedito = 19 & GbS021 & - & Spain & Pre-1950 & $\mathrm{S} / \mathrm{F}$ & + & H_24 & SSH & MNCNM & J.J. Negro \\
\hline 17243 & GbS022 & Madrid & Spain & Late s.XIX & $\mathrm{S} / \mathrm{F}$ & + & H_25 & $\mathrm{CSH}$ & MNCNM & J.J. Negro \\
\hline
\end{tabular}


Appendix 1 Continued

\begin{tabular}{|c|c|c|c|c|c|c|c|c|c|c|}
\hline Sample ID & $\begin{array}{l}\text { Sample } \\
\text { code }\end{array}$ & $\begin{array}{l}\text { Locality/ } \\
\text { area }\end{array}$ & Country & Date & Tissue $^{1}$ & Data $^{2}$ & Haplotype & Population & Contributor ${ }^{3}$ & Sampler \\
\hline 97-0169.DARP6827 & GbS023 & $\begin{array}{l}\text { Ribera de } \\
\text { Cordos (Pyr.) }\end{array}$ & Spain & 1994 & $\mathrm{~S} / \mathrm{F}$ & + & H_01 & NSC & MZB & E. Garcia \\
\hline 92-0184 & GbS024 & Toledo & Spain & 1943 & $\mathrm{~S} / \mathrm{F}$ & + & H_01 & $\mathrm{CSH}$ & MZB & E. Garcia \\
\hline- & GbS025 & Pyrenees & Spain & 1896 & $\mathrm{~S} / \mathrm{F}$ & - & & & MHNG & A. Fayard \\
\hline- & GbS026 & Sardinia & Italy & 1913 & $\mathrm{~S} / \mathrm{F}$ & - & & & MHNG & A. Fayard \\
\hline- & GbS027 & Sardinia & Italy & 1935 & $\mathrm{~S} / \mathrm{F}$ & + & H_33 & SAR & MHNG & A. Fayard \\
\hline- & GbS028 & Sardinia & Italy & 1907 & $\mathrm{~S} / \mathrm{F}$ & + & H_01 & SAR & MHNG & A. Fayard \\
\hline- & GbS029 & Sardinia & Italy & 1912 & $\mathrm{~S} / \mathrm{F}$ & - & & & MHNG & A. Fayard \\
\hline- & GbS030 & Sardinia & Italy & 1906 & $\mathrm{~S} / \mathrm{F}$ & + & H_36 & SAR & MHNG & A. Fayard \\
\hline- & GbS031 & Presles & France & - & $\mathrm{S} / \mathrm{F}$ & + & H_40 & ALP & MHNG & A. Fayard \\
\hline- & GbS032 & Sardinia & Italy & - & $\mathrm{S} / \mathrm{F}$ & + & H_35 & SAR & MHNG & A. Fayard \\
\hline- & GbS033 & Crete & Greece & 1998 & $\mathrm{~S} / \mathrm{F}$ & + & H_26 & CRE & - & S. Xirouchakis \\
\hline- & GbS034 & Jaén (Andalusia) & Spain & Pre-1950 & $\mathrm{S} / \mathrm{F}$ & + & H_27 & SSH & M. López, Private & J. Muñoz \\
\hline- & GbS035 & Jaén (Andalusia) & Spain & 1930-1932 & $\mathrm{S} / \mathrm{F}$ & + & H_24 & SSH & M. López, Private & J. Muñoz \\
\hline- & GbS036 & Jaén (Andalusia) & Spain & $1910-1920$ & $\mathrm{~S} / \mathrm{F}$ & + & H_24 & SSH & Dña. Eloisa, Private & J. Muñoz \\
\hline- & GbS037 & $\begin{array}{l}\text { Granada } \\
\text { (Andalusia) }\end{array}$ & Spain & 1874 & $\mathrm{~S} / \mathrm{F}$ & + & H_27 & SSH & MCG & J. Muñoz \\
\hline- & GbS038 & Murcia & Spain & 1950 & $\mathrm{~S} / \mathrm{F}$ & + & H_27 & SSH & - & J.J. Negro \\
\hline- & GbS039 & Navarra & Spain & Pre-1950 & $\mathrm{S} / \mathrm{F}$ & - & & & Gov. of Navarra & A. Senosiain \\
\hline- & GbS040 & Navarra & Spain & $40 \mathrm{~s}$ & $\mathrm{~S} / \mathrm{F}$ & - & & & Gov. of Navarra & A. Senosiain \\
\hline- & GbS041 & Crete & Greece & 1997 & $\mathrm{~S} / \mathrm{F}$ & - & - & & & S. Xirouchakis \\
\hline- & GbS042 & Crete & Greece & 1980 & $\mathrm{~S} / \mathrm{F}$ & + & H_28 & CRE & - & S. Xirouchakis \\
\hline- & GbS043 & Crete & Greece & - & $\mathrm{S} / \mathrm{F}$ & - & - & & & S. Xirouchakis \\
\hline- & GbS046 & - & Ethiopia & 2000 & $\mathrm{~S} / \mathrm{F}$ & + & H_29 & ETH & - & J. Juste \\
\hline- & GbS047 & Crete & Greece & 2000 & $\mathrm{~S} / \mathrm{F}$ & + & H_26 & CRE & - & S. Xirouchakis \\
\hline 0407 & GbS048 & Sardinia & Italy & - & $\mathrm{S} / \mathrm{F}$ & + & H_33 & SAR & SWNS & B. Gautschi* \\
\hline 2164 & GbS049 & Malans & Switzerland & - & $\mathrm{S} / \mathrm{F}$ & + & H_31 & ALP & SWNS & B. Gautschi* \\
\hline 2270 & GbS050 & Andeer & Switzerland & 1850 & $\mathrm{~S} / \mathrm{F}$ & + & H_32 & ALP & SWNS & B. Gautschi* \\
\hline 2243 & GbS051 & Wattensburg & Switzerland & 1852 & $\mathrm{~S} / \mathrm{F}$ & + & H_31 & ALP & SWNS & B. Gautschi* \\
\hline 0406a & GbS052 & - & Switzerland & $1850-1851$ & $\mathrm{~S} / \mathrm{F}$ & + & H_31 & ALP & SWNS & B. Gautschi* \\
\hline 7206 & GbS053 & Sardinia & Italy & - & $\mathrm{S} / \mathrm{F}$ & + & $\mathrm{H} \_41$ & SAR & MZS & B. Gautschi* \\
\hline 7207 & GbS054 & Conoraza & Italy & 1885 & $\mathrm{~S} / \mathrm{F}$ & + & H_31 & SAR & MZS & B. Gautschi* \\
\hline 7208 & GbS055 & Sardinia & Italy & 1892 & $\mathrm{~S} / \mathrm{F}$ & + & H_33 & SAR & MZS & B. Gautschi* \\
\hline 7209 & GbS056 & Sardinia & Italy & 1901 & $\mathrm{~S} / \mathrm{F}$ & + & H_36 & SAR & MZS & B. Gautschi* \\
\hline 7210 & GbS057 & Sardinia & Italy & 1906 & $\mathrm{~S} / \mathrm{F}$ & + & H_33 & SAR & MZS & B. Gautschi* \\
\hline 7211 & GbS058 & Sardinia & Italy & 1907 & $\mathrm{~S} / \mathrm{F}$ & + & H_33 & SAR & MZS & B. Gautschi* \\
\hline 7212 & GbS059 & Sardinia & Italy & 1907 & $\mathrm{~S} / \mathrm{F}$ & + & H_33 & SAR & MZS & B. Gautschi* \\
\hline 7213 & GbS060 & Sardinia & Italy & 1908 & $\mathrm{~S} / \mathrm{F}$ & + & H_42 & SAR & MZS & B. Gautschi* \\
\hline 7214 & GbS061 & - & Ethiopia & 1887 & $\mathrm{~S} / \mathrm{F}$ & + & H_30 & ETH & MZS & B. Gautschi* \\
\hline Nr.109 & GbS062 & Glarus & Switzerland & 1830 & $\mathrm{~S} / \mathrm{F}$ & + & H_31 & ALP & NMB & B. Gautschi* \\
\hline 1036716 & GbS063 & - & North Africa & - & $\mathrm{S} / \mathrm{F}$ & + & H_30 & NAF & NMBB & B. Gautschi* \\
\hline
\end{tabular}




\begin{tabular}{|c|c|c|c|c|c|c|c|c|c|c|}
\hline Sample ID & $\begin{array}{l}\text { Sample } \\
\text { code }\end{array}$ & $\begin{array}{l}\text { Locality/ } \\
\text { area }\end{array}$ & Country & Date & Tissue $^{1}$ & Data $^{2}$ & Haplotype & Population & Contributor ${ }^{3}$ & Sampler \\
\hline 1025773 & GbS064 & Grindelwald & Switzerland & 1826 & $\mathrm{~S} / \mathrm{F}$ & - & & & NMBB & B. Gautschi* \\
\hline 1025775 & GbS065 & Graubünden & Switzerland & 1847 & $\mathrm{~S} / \mathrm{F}$ & - & & & NMBB & B. Gautschi* \\
\hline 1025774 & GbS066 & Brienzersee & Switzerland & 1823 & $\mathrm{~S} / \mathrm{F}$ & + & H_31 & ALP & NMBB & B. Gautschi* \\
\hline 1036711 & GbS067 & Sardinia & Italy & 1888 & $\mathrm{~S} / \mathrm{F}$ & + & H_36 & SAR & NMBB & B. Gautschi* \\
\hline 1029615 & GbS068 & Zuoz & Switzerland & 1854 & $\mathrm{~S} / \mathrm{F}$ & + & H_27 & ALP & NMBB & B. Gautschi* \\
\hline 1029619 & GbS069 & Zweilütschinen & Switzerland & 1854 & $\mathrm{~S} / \mathrm{F}$ & + & H_32 & ALP & NMBB & B. Gautschi* \\
\hline 1040559 & GbS070 & - & Ethiopia & 1959 & $\mathrm{~S} / \mathrm{F}$ & + & H_30 & ETH & NMBB & B. Gautschi* \\
\hline 1040558 & GbS071 & - & Ethiopia & 1959 & $\mathrm{~S} / \mathrm{F}$ & + & H_30 & ETH & NMBB & B. Gautschi* \\
\hline 1040557 & GbS072 & Asco (Corsica) & France & 1957 & $\mathrm{~S} / \mathrm{F}$ & - & & & NMBB & B. Gautschi* \\
\hline MHNG 0007.36 & GbS073 & Graubünden & Switzerland & 1820 & $\mathrm{~S} / \mathrm{F}$ & + & H_33 & ALP & NMG & B. Gautschi* \\
\hline MHNG 0799.97 & GbS074 & Martigny & Switzerland & 1861 & $\mathrm{~S} / \mathrm{F}$ & + & H_27 & ALP & NMG & B. Gautschi* \\
\hline MHNG 0799.62 & GbS075 & - & Switzerland & - & $\mathrm{S} / \mathrm{F}$ & - & & & NMG & B. Gautschi* \\
\hline $92.3184 \mathrm{~A}$ & GbS076 & Andeer & Switzerland & - & $\mathrm{S} / \mathrm{F}$ & + & H_27 & ALP & MHN & B. Gautschi* \\
\hline 92.3134 B & GbS077 & Oberland & Switzerland & 1850 & $\mathrm{~S} / \mathrm{F}$ & + & H_31 & ALP & MHN & B. Gautschi* \\
\hline $92.3184 \mathrm{C}$ & GbS078 & Brig (Wallis) & Switzerland & 1833 & $\mathrm{~S} / \mathrm{F}$ & + & H_31 & ALP & MHN & B. Gautschi* \\
\hline 73771 & GbS079 & Himalaya & India & 1839 & $\mathrm{~S} / \mathrm{F}$ & + & H_39 & CAS & NMW & B. Gautschi* \\
\hline 73772 & GbS080 & - & Switzerland & 1878 & $\mathrm{~S} / \mathrm{F}$ & - & & & NMW & B. Gautschi* \\
\hline 73774 & GbS081 & $\begin{array}{l}\text { Granada } \\
\text { (Andalusia) }\end{array}$ & Spain & 1879 & $\mathrm{~S} / \mathrm{F}$ & + & H_34 & $\mathrm{SSH}$ & NMW & B. Gautschi* \\
\hline 37761 & GbS082 & Steiermark & Austria & 1809 & $\mathrm{~S} / \mathrm{F}$ & - & & & NMW & B. Gautschi* \\
\hline 84422 & GbS083 & - & Austria & - & $\mathrm{S} / \mathrm{F}$ & + & H_43 & ALP & NMW & B. Gautschi* \\
\hline 4591 & GbS084 & - & Kaukasus & 1904 & $\mathrm{~S} / \mathrm{F}$ & + & H_27 & CAU & NMW & B. Gautschi* \\
\hline 14711 & GbS085 & - & Switzerland & 1818 & $\mathrm{~S} / \mathrm{F}$ & + & H_31 & ALP & NSF & B. Gautschi* \\
\hline 10700 & GbS086 & - & Ethiopia & 1900 & $\mathrm{~S} / \mathrm{F}$ & + & H_30 & ETH & NSF & B. Gautschi* \\
\hline 10690 & GbS087 & - & Greece & 1899 & $\mathrm{~S} / \mathrm{F}$ & + & H_44 & GRE & NSF & B. Gautschi* \\
\hline 10691 & GbS088 & - & Greece & 1899 & $\mathrm{~S} / \mathrm{F}$ & + & H_45 & GRE & NSF & B. Gautschi* \\
\hline 14710 & GbS089 & - & Greece & 1905 & $\mathrm{~S} / \mathrm{F}$ & + & H_45 & GRE & NSF & B. Gautschi* \\
\hline 10692 & GbS090 & $\begin{array}{l}\text { Granada } \\
\text { (Andalusia) }\end{array}$ & Spain & 1899 & $\mathrm{~S} / \mathrm{F}$ & + & H_27 & SSH & NSF & B. Gautschi* \\
\hline ORN 1129 & GbS091 & Zermatt (Wallis) & Switzerland & 1839 & $\mathrm{~S} / \mathrm{F}$ & + & H_31 & ALP & MZL & B. Gautschi* \\
\hline ORN 429 & GbS092 & Wallis & Switzerland & 1886 & $\mathrm{~S} / \mathrm{F}$ & + & H_27 & ALP & MZL & B. Gautschi* \\
\hline ORN 40a & GbS093 & Sardinia & Italy & 1915 & $\mathrm{~S} / \mathrm{F}$ & + & H_33 & SAR & MZL & B. Gautschi* \\
\hline 1104 & GbS094 & Maggiatal & Switzerland & 1869 & $\mathrm{~S} / \mathrm{F}$ & - & & & NSStGM & B. Gautschi* \\
\hline 1106 & GbS095 & Nauders (Tirol) & Italia & 1871 & $\mathrm{~S} / \mathrm{F}$ & + & H_31 & ALP & NSStGM & B. Gautschi* \\
\hline 1109 & GbS096 & Parnassus & Greece & 1885 & $\mathrm{~S} / \mathrm{F}$ & + & H_46 & GRE & NSStGM & B. Gautschi* \\
\hline Nr.23 & GbS097 & $\begin{array}{l}\text { Naryn } \\
\text { (Turkestan) }\end{array}$ & Kazakhstan & 1913 & $\mathrm{~S} / \mathrm{F}$ & + & H_13 & CAS & HNS & B. Gautschi* \\
\hline Nr.235 & GbS098 & $\begin{array}{l}\text { Naryn } \\
\text { (Turkestan) }\end{array}$ & Kazakhstan & 1910 & $\mathrm{~S} / \mathrm{F}$ & + & H_33 & CAS & HNS & B. Gautschi* \\
\hline Nr.199 & GbS099 & Kaukasus & Kaukasus & 1912 & $\mathrm{~S} / \mathrm{F}$ & + & H_34 & CAU & HNS & B. Gautschi* \\
\hline 0535 & GbS100 & Sardinia & Italy & 1985 & $\mathrm{~S} / \mathrm{F}$ & + & H_33 & SAR & MFSNU & B. Gautschi* \\
\hline
\end{tabular}


Appendix 1 Continued

\begin{tabular}{|c|c|c|c|c|c|c|c|c|c|c|c|}
\hline Sample ID & $\begin{array}{l}\text { Sample } \\
\text { code }\end{array}$ & $\begin{array}{l}\text { Locality/ } \\
\text { area }\end{array}$ & Country & Date & Tissue $^{1}$ & Data $^{2}$ & Haplotype & Population & Contributor ${ }^{3}$ & Sampler & \\
\hline 1955.6.N.20.198 & GbS101 & $\begin{array}{l}\text { Bagnères de } \\
\text { Bigorre (Pyr.) }\end{array}$ & France & 1955 & $\mathrm{~S} / \mathrm{F}$ & + & H_02 & NSH & BMNHZMT & B. Gautschi* & \\
\hline 1955.6N20.169 & GbS102 & $\begin{array}{l}\text { Valley of Magna, } \\
\text { near Nice }\end{array}$ & France & 1955 & $\mathrm{~S} / \mathrm{F}$ & + & H_34 & ALP & BMNHZMT & B. Gautschi* & \\
\hline 1874.4.9.1 & GbS103 & Jaén (Andalusia) & Spain & 1872 & $\mathrm{~S} / \mathrm{F}$ & - & & & BMNHZMT & B. Gautschi* & \\
\hline 1891.4.11.19 & GbS104 & - & Spain & 1891 & $\mathrm{~S} / \mathrm{F}$ & + & H_27 & IBP & BMNHZMT & B. Gautschi* & \\
\hline 1873.1.2.1 & GbS105 & $\begin{array}{l}\text { Málaga } \\
\text { (Andalusia) }\end{array}$ & Spain & 1869 & $\mathrm{~S} / \mathrm{F}$ & + & H_02 & SSH & BMNHZMT & B. Gautschi* & \\
\hline- & GbS106 & Kaukasus & Kaukasus & 1900 & $\mathrm{~S} / \mathrm{F}$ & + & H_47 & CAU & MNB & B. Gautschi* & \\
\hline $106 \times 250$ & GbS107 & - & Greece & 1908 & $\mathrm{~S} / \mathrm{F}$ & + & H_46 & GRE & MNB & B. Gautschi* & \\
\hline В 635 & GbS108 & - & Greece & 1908 & $\mathrm{~S} / \mathrm{F}$ & + & H_25 & GRE & MNB & B. Gautschi* & \\
\hline- & GbS109 & Pyrenees & Spain & 1904 & $\mathrm{~S} / \mathrm{F}$ & + & H_35 & $\mathrm{NSH}$ & MNB & B. Gautschi* & \\
\hline 171 & GbS110 & - & Switzerland & 1891 & $\mathrm{~S} / \mathrm{F}$ & + & H_33 & ALP & MCHN & B. Gautschi* & \\
\hline 173 & GbS111 & - & Switzerland & 1881 & $\mathrm{~S} / \mathrm{F}$ & + & H_31 & ALP & MCHN & B. Gautschi* & \\
\hline 174 & GbS112 & - & Switzerland & 1891 & $\mathrm{~S} / \mathrm{F}$ & + & H_35 & ALP & MCHN & B. Gautschi* & \\
\hline 172 & GbS113 & - & Switzerland & 1891 & $\mathrm{~S} / \mathrm{F}$ & + & H_36 & ALP & MCHN & B. Gautschi* & \\
\hline 25 & GbS114 & Geneva & Switzerland & 1809 & $\mathrm{~S} / \mathrm{F}$ & + & H_31 & ALP & MRSNT & B. Gautschi* & هـ \\
\hline 11 & GbS115 & Sardinia & Italy & 1906 & $\mathrm{~S} / \mathrm{F}$ & + & H_33 & SAR & MAKB & B. Gautschi* & $I$ \\
\hline 13 & GbS116 & Sardinia & Italy & 1906 & $\mathrm{~S} / \mathrm{F}$ & + & H_36 & SAR & MAKB & B. Gautschi* & 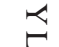 \\
\hline 15 & GbS117 & Lamentite & Albania & 1924 & $\mathrm{~S} / \mathrm{F}$ & + & H_46 & GRE & MAKB & B. Gautschi* & 0 \\
\hline 7 & GbS118 & Thian Shan & Kazakhstan & 1904 & $\mathrm{~S} / \mathrm{F}$ & + & H_48 & CAS & MAKB & B. Gautschi* & $\Omega$ \\
\hline 10 & GbS119 & Sardinia & Italy & 1905 & $\mathrm{~S} / \mathrm{F}$ & - & & & MAKB & B. Gautschi* & $0^{\pi}$ \\
\hline 22 & GbS120 & Sardinia & Italy & 1915 & $\mathrm{~S} / \mathrm{F}$ & + & H_33 & SAR & MAKB & B. Gautschi* & $\Omega$ \\
\hline- & GbS121 & $\begin{array}{l}\text { Málaga } \\
\text { (Andalusia) }\end{array}$ & Spain & 1900 & $\mathrm{~S} / \mathrm{F}$ & + & H_24 & SSH & MAKB & B. Gautschi* & D \\
\hline 25 & GbS122 & $\begin{array}{l}\text { Petrowsk } \\
\text { (Dagestan) }\end{array}$ & Russia & 1900 & $\mathrm{~S} / \mathrm{F}$ & - & & & MAKB & B. Gautschi* & 玟 \\
\hline 9 & GbS123 & $\begin{array}{l}\text { Khalatase Ladakh } \\
\text { (Kashmir) }\end{array}$ & India & 1933 & $\mathrm{~S} / \mathrm{F}$ & + & H_49 & CAS & MAKB & B. Gautschi* & $\begin{array}{l}0 \\
0 \\
0\end{array}$ \\
\hline 38 & GbS124 & $\begin{array}{l}\text { Ladaka } \\
\text { (Kashmir) }\end{array}$ & India & 1934 & $\mathrm{~S} / \mathrm{F}$ & - & & & МАKB & B. Gautschi* & $D_{0}^{+1}$ \\
\hline- & GbS125 & Nislam & Kaukasus & 1904 & $\mathrm{~S} / \mathrm{F}$ & + & H_50 & CAU & MAKB & B. Gautschi* & $\theta$ \\
\hline- & GbS126 & - & Tunisia & 1887 & $\mathrm{~S} / \mathrm{F}$ & + & H_43 & NAF & MAKB & B. Gautschi* & TI \\
\hline 24 & GbS127 & Kisslowodosk & Kaukasus & 1890 & $\mathrm{~S} / \mathrm{F}$ & - & & & MAKB & B. Gautschi* & \\
\hline 12 & GbS128 & Sardinia & Italy & 1905 & $\mathrm{~S} / \mathrm{F}$ & + & H_41 & SAR & MAKB & B. Gautschi* & $\lesssim$ \\
\hline BNM 3647 & GbS129 & Ftan, Val Tasua & Switzerland & 1859 & $\mathrm{~S} / \mathrm{F}$ & + & H_27 & ALP & BNMC & B. Gautschi* & 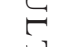 \\
\hline NMO 30157 & GbS130 & - & Ethiopia & 1886 & $\mathrm{~S} / \mathrm{F}$ & + & H_30 & ETH & NMO & B. Gautschi* & 己 \\
\hline $7040 \mathrm{U}$ & GbS131 & - & Africa & 1882 & $\mathrm{~S} / \mathrm{F}$ & + & H_30 & AFR & MS & B. Gautschi* & 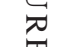 \\
\hline- & GbS132 & Crete & Greece & August 2000 & $\mathrm{~S} / \mathrm{F}$ & + & H_37 & CRE & - & S.Xirouchakis & U \\
\hline- & GbS136 & - & Yemen's Republic & 1997 & $\mathrm{~F}$ & + & H_31 & YEM & - & J.A. Donázar & $\omega$ \\
\hline 1955.6 N20.211 & GbS137 & - & South Africa & 1955 & $\mathrm{~F}$ & + & H_30 & SAF & BMNHZMT & B. Martínez & ర్రి \\
\hline
\end{tabular}


Appendix 1 Continued

\begin{tabular}{|c|c|c|c|c|c|c|c|c|c|c|}
\hline Sample ID & $\begin{array}{l}\text { Sample } \\
\text { code }\end{array}$ & $\begin{array}{l}\text { Locality/ } \\
\text { area }\end{array}$ & Country & Date & Tissue $^{1}$ & Data $^{2}$ & Haplotype & Population & Contributor 3 & Sampler \\
\hline- & GbS138 & $\begin{array}{l}\text { Córdoba } \\
\text { (Andalusia) }\end{array}$ & Spain & $20 \mathrm{~s}$ & $\mathrm{~F}$ & + & H_24 & $\mathrm{SSH}$ & - & J.J. Negro \\
\hline 17330 & GbS139 & - & Switzerland & & Fp & + & H_01 & ALP & NHMN & B. Martínez \\
\hline 17329 & GbS140 & Pyrenees & Spain & 1872 & Fp & - & & & NHMN & B. Martínez \\
\hline 17327 & GbS141 & - & Algeria & 1856 & Fp & + & H_27 & NAF & NHMN & B. Martínez \\
\hline 17326 & GbS142 & Pyrenees & Spain & 1872 & Fp & + & H_01 & NSH & NHMN & B. Martínez \\
\hline 17321 & GbS143 & Pyrenees & Spain & & $\mathrm{Fp}$ & + & H_35 & NSH & NHMN & B. Martínez \\
\hline 17328 & GbS144 & Bayona & France & 1852 & Fp & - & & & NHMN & B. Martínez \\
\hline 17322 & GbS145 & - & Switzerland & & Fp & + & H_24 & ALP & NHMN & B. Martínez \\
\hline 17323 & GbS146 & Pyrenees & Spain & & Fp & + & H_01 & NSH & NHMN & B. Martínez \\
\hline 17324 & GbS147 & Pyrenees & Spain & 1868 & Fp & + & H_01 & NSH & NHMN & B. Martínez \\
\hline 17325 & GbS148 & $\begin{array}{l}\text { St Jean Pied } \\
\text { de Port (Pyr.) }\end{array}$ & France & 1872 & $\mathrm{Fp}$ & - & & & NHMN & B. Martínez \\
\hline 31753 & GbS149 & Pyrenees & Spain & 1920-30 & Fp & + & H_36 & $\mathrm{NSH}$ & MBC & B. Martínez \\
\hline 31763 & GbS150 & Pyrenees & Spain & 1920-30 & Fp & - & & & MBC & B. Martínez \\
\hline SMF 1837 & GbS151 & - & South Africa & 1837 & Fp & + & H_30 & SAF & NSF & - \\
\hline
\end{tabular}

1The type of tissue sampled is indicated as B, blood; S/F, skin/feather; F, feather; M, muscle; Fp, footpad.

2Data indicate whether sequence data was finally obtained (+) or not (-); in this latter case it was always due to unsuccessful PCR amplifications.

3Institutions or individuals contributing the samples are listed. FCQ: Fundación para la Conservación del Quebrantahuesos; BVBN: Bearded Vulture Breeding Network; CCG: Centro de Cría ‘Guadalentín’; NHMT: Natural History Museum of Toulousse; EBD: Estación Biológica de Doñana, Seville; MNCNM: Museo Nacional de Ciencias Naturales de Madrid; MZB: Museu de Zoologia de Barcelona; MHNG: Muséum d’histoire NaturelLe de Grenoble; MCG: Museo de Ciencias de Granada; SWNS: Stadt Wintherthur Naturwissenschafltiche Sammlungen; MZS: Museo Zoologico de 'La Specola' de Firenze; NMB: Naturhistorisches Museum, Basel; NMBB: Naturhistorisches Museum der Burgergemeinde, Bern; NHMG: Natural History Museum of Geneva; MHNN: Museum d’Histoire Naturelle de Neuchâtel; NMW: Naturhistorisches Museum, Wien; NSF: Naturmuseum Senckenberg, Frankfurt; MZL: Musée de Zoologie de Lausane; NSStGM: Naturmuseum Stiftung St Gallen Museen; HNS: Haus der Natur, Salzburg; MFSNU: Museo Friulano di Stori Naturlale, Udine; BMNHZMT: British Museum Natural History Zoological Museum, Tring; MNB: Museum für Naturkunde, Berlin; MCHNN: Musée Cantonal d'histoire Naturelle de Nord; MRSNT: Museo Regionale di Scienze Naturali, Torino; MAKB: Museum Alexander König, Bonn; BNMC: Bündner Natur-Museum, Chur; NMO: Naturmuseum Olten; MS: Museum Solothurn; NHMN: Natural History Museum of Nantes; MBC: Marchant Baréges Collections.

*Samples provided by B. Gautschi as DNA extracts. 